\title{
Animal Exploitation and Behaviour of the Latest Middle Stone Age Societies in the Middle Nile Valley: Archaeozoological and Taphonomic Analysis of Late Pleistocene Fauna from the Affad Basin, Sudan
}

\author{
Marta Osypińska • Piotr Osypiński
}

Published online: 25 May 2016

(C) The Author(s) 2016. This article is published with open access at Springerlink.com

\begin{abstract}
With the research on the issue in its initial phases, the behaviour and hunting strategies of MSA communities inhabiting the Nile Valley in the Late and Terminal Pleistocene have been fragmentarily recognised thus far. Osteological materials from the area of the Affad Basin in the Middle Nile Valley, recorded in archaeological contexts and dated to the sixteenth millennium BP using OSL methods, have significantly enhanced our knowledge in this regard. It is the first time that an opportunity has occurred to construct a reliable model of the environment exploitation and the behaviour of human groups producing lithic tools using Levallois methods in the Terminal Pleistocene. Archaeozoological analyses have allowed the identification of taxa, species and anatomical origin of remains and enabled the establishment of a database of osteometric measurements. The animals hunted in the Sudanese Nile Valley during the Terminal Pleistocene have been classified with a view to refer the data to the results of analogous studies on MSA in South Africa. The behaviour of the communities occupying the Affad Basin 15,000 years ago was connected to the environment of the tree-covered, swampy savannah and extensive backwaters. Medium-sized antelope (kobus) was hunted most often. People hunted also, albeit less frequently, for large ruminants (buffalo), guenons and large
\end{abstract}

\footnotetext{
M. Osypińska $(\bowtie)$

Institute of Archaeology and Ethnology Polish Academy of

Sciences, Rubiez 46, 62-612 Poznan, Poland

e-mail: archeozoo@o2.pl

P. Osypiński

Patrimonium Foundation, Wodna 27, 61-781 Poznan, Poland
}

rodents. Remains of fish and mega-fauna (hippopotamus and elephant) have been found in isolated concentrations, away from the camp sites. Remains of molluscs or ostrich eggs have not been registered. The condition of the osteological materials, notably their anatomical distribution, is shown to have been largely affected by wetland environment, rich in iron and manganese.

Résumé Le comportement et les stratégies de chasse des communautés du paléolithique moyen habitant la Vallée du Nil dans le Pléistocène supérieur ne sont identifiés que d'une manière fragmentaire et à un niveau très sommaire. Les matériaux ostéologiques du 16e millénaire avant le présent trouvés sur le territoire du Bassin d'Affad dans la moyenne Vallée du Nil, enregistrés sur les sites archéologiques et datés avec des méthodes OSL viennent compléter les informations disponibles d'une manière importante. Pour la première fois sur ce territoire est apparue la possibilité de créer un modèle, plausible et basé sur un contexte archéologique, à la fois d'exploitation de l'environnement et de comportement de groupes humains liés à l'épisode tardif d'utilisation de la technique Levallois classique, dans le Pléistocène supérieur. Les analyses archéologiques ont permis l'identification des taxons, des espèces et des débris d'origine anatomique, ainsi que la création d'une base de mesures ostéométriques. De plus, pour la première fois dans la Vallée du Nil dans le Pléistocène supérieur, une classification de gibier a été élaborée, analogiquement aux méthodes appliquées dans les études du paléolithique moyen en Afrique du Sud. Le comportement des communautés habitant le Bassin d'Affad il y a 15 mille ans était lié à un environnement 
de savane arborée, marécageuse avec des marais étendus. La chasse se concentrait sur les antilopes de taille moyenne (cobe). On chassait également, mais à un moindre degré, des ruminants plus grands (buffles), des Chlorocebus et de grands rongeurs. On retrouve aussi des restes de poissons et de mégafaune (hippopotames et éléphants), dans des concentrations isolées, loin de leurs habitats. La présence des restes de mollusques ou d'œufs d'autruche n'a pas été constatée. L'environnement humide, riche en fer et manganèse, a eu une influence déterminante sur l'état de conservation des matériaux ostéologiques, et surtout sur leur décomposition anatomique.

Keywords Northeastern Africa · Middle Stone Age · Terminal Pleistocene $\cdot$ Hunting strategies .

Archaeozoology Taphonomy

\section{Introduction}

The current state of faunal knowledge in archaeological contexts dating to the Late Pleistocene, in the area of the Sudanese part of the Nile Valley, is still limited (Bate 1951; Chaix et al. 2000; Gautier 1968, 1987; Gautier et al. 2012; Peters 1989b, 1992; cf. Steele 2012). Discovered in 2003 and rich in mineralised animal remains, the complex of sites at Affad (northern province, Sudan) stands out as an essential element that will enhance our knowledge of the fauna, environment and behaviour of the communities living in Upper Nubia at the end of the Pleistocene (Osypiński et al. 2011). Research conducted in the years 2012-2014 in the Affad Basin was aimed at obtaining further osteological assemblages from dated archaeological contexts, thus allowing us to develop and rectify previously prevailing ideas (Fig. 1).

Geomorphological research results reveal that the wide plain around Affad was formed during alluvial and aeolian sedimentation in periods preceding the fall of MIS2 (Osypiński et al. 2016). Sediments rich in archaeological artefacts are related to the late stage of MIS2 in the sixteenth millennium BP. A series of silts covering the archaeological sites resulted in an excellent state of preservation of the lithic artefacts and remains of structures and hearths. Most importantly, it resulted in the mineralisation and good state of preservation of the animal remains.

An essential part of the project consisted of the acquisition of archaeological sources at Affad 23, with partly preserved vertical and horizontal stratigraphy.
Furthermore, a complex of analogously dated sites marked by evident functional differentiation (camps, killing/scavenging and butchering sites, and those for fishing) was registered in the area of the Affad Basin. The research yielded a total of 6102 animal remains; the fragments of bones and teeth were either eroded and scattered on the site's surface or still embedded in Terminal Pleistocene sediments.

While several mineralised bone surface scatters were registered at the sites during the preliminary stage of research, assemblages excavated from stratified sediments at Affad 23, Affad 110 and Affad 111 were found to be much more valuable (Fig. 2).

The main work was focused on site Affad 23. We explored three general zones where archaeological evidence occurred: northern (trench 2012/B, Fig. 3, with surrounding areas labelled as $\mathrm{D}, \mathrm{J}$ and $\mathrm{K}$ as well as 2012/C); southwestern, some $150 \mathrm{~m}$ from the first (trenches 2013/F-I, Q, Fig. 4 and extended 1-m-wide sondages $\mathrm{N}-\mathrm{P}$ ); and southern, located $50 \mathrm{~m}$ farther south (trenches 2013/L-M, Fig. 5). Unless the need for brevity prevented us, the excavated sediments were screened (2$\mathrm{mm}$ mesh size); but generally, exploration technique involved brushes and trowels and three-dimensional recording of artefacts larger than $1 \mathrm{~cm}$. The same methods were used while excavating Affad 110 and Affad 111.

Sedimentation history of the explored area reconstructed due to present research at Affad 23 revealed accumulation of sand and silt units, dated by OSL method (Kalicki and Olszak 2016) to the period $15.9 \pm 1.75 \mathrm{ka}$ (UJK-OSL-35) and 15.1 \pm 1.66 (UJK-OSL-37), over calcareous silts of LGM alluviation dated to $21.1 \pm 2.32 \mathrm{ka}$ (UJK-OSL-36). Sand bar or channel bank beach was a place of human seasonal settlement. An ancient ground depression (noted in the northwestern part of trench 2013/F-I) had been filled with occupation wastes, and further sealed with another layer of silt of the Nile overflow dated to $15.3 \pm 1.68 \mathrm{ka}$ (UJK-OSL34). Occupation zones located above 253.00 a.s.1. with light wooden structures, pits and hearths did not produce sealing sediment evidence. However, the presence of small cut features as well as clear spatial clustering of lithics (confirmed with refits) and bones suggests preservation of original horizontal stratigraphy on the site. Early Holocene history of landscape formation is marked with crossbed channels filled with gravels transported to the river, most probably in its modern location, $2.5 \mathrm{~km}$ to the south. These last gravels contained reworked 

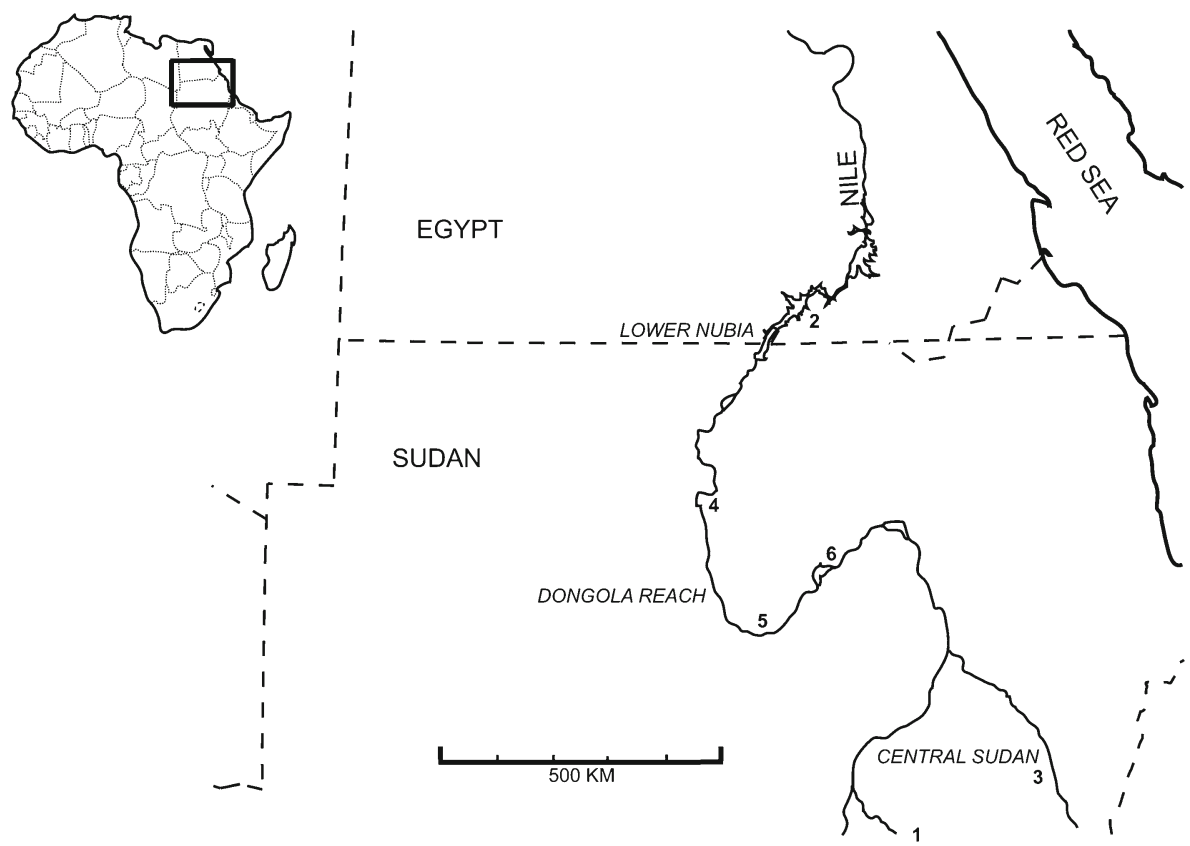

Fig. 1 Archaeological sites of Late Pleistocene age with faunal remains in the Sudanese part of the Nile Valley. 1 Singa, Abu Hugar (Bate 1951), 2 Wadi Halfa area sites (Gautier 1968, 1987), 3

single stone artefacts of both Pleistocene and Holocene origin, but no signs of in situ early Holocene evidence.

Taxonomic (cultural, techno-complex) evaluation of the lithic assemblage of Affad 23 points exclusively to Levallois lithic traditions, without intrusive or transitional (progressive) elements related to the LSA: backed
Kashm el-Girba (Peters 1989b, 1992), 4 Kaddanarti, Kabrinarti (Chaix et al. 2000), 5 Affad Basin (Osypiński et al. 2011), 6 Umm Rahau (Gautier et al. 2012)

implements, blade methods of blank production (Osypiński et al. 2011; Osypiński and Osypińska 2015). Dating of the Affad archaeology to the onset of African Humid Period finds a distant parallel in the Sebilian industry of Lower Nubia and-following Marks' (1968) idea of its origins - the Tchitolian of Uganda, and we need to underline its unique character

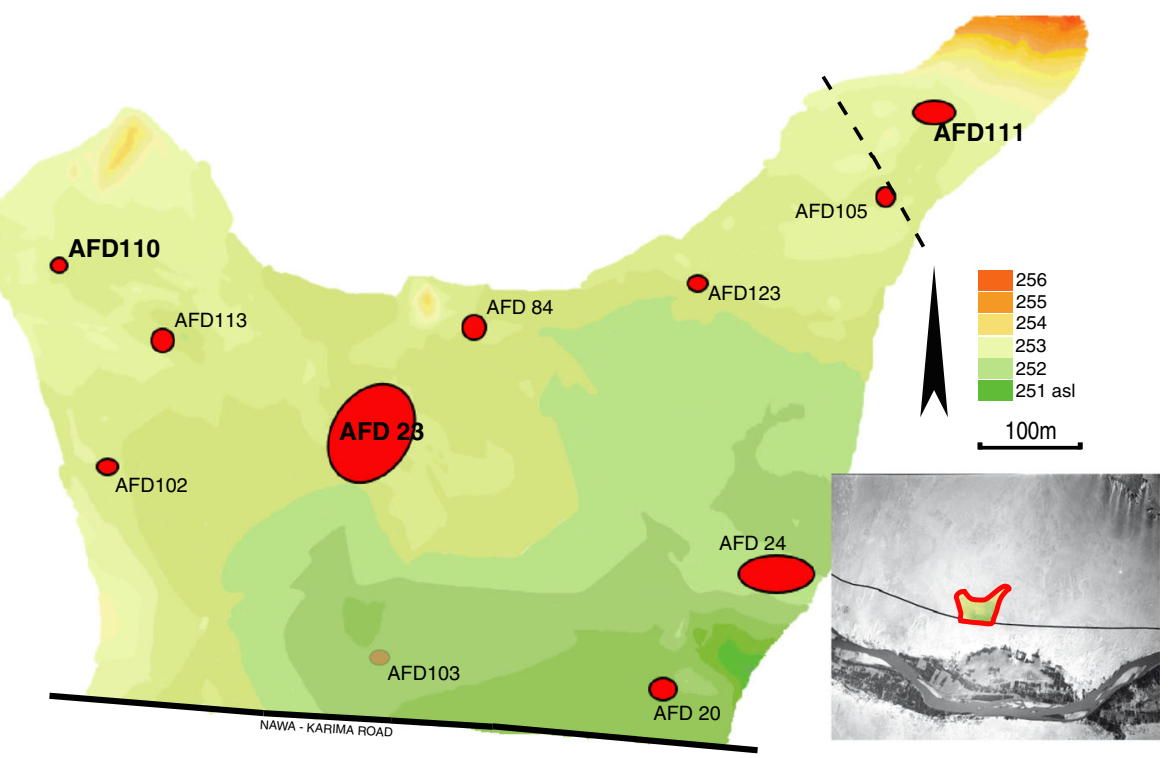

Fig. 2 Affad Basin, location of the main archaeological sites of Terminal Pleistocene age with faunal remains (prep. by P. Osypiński) 


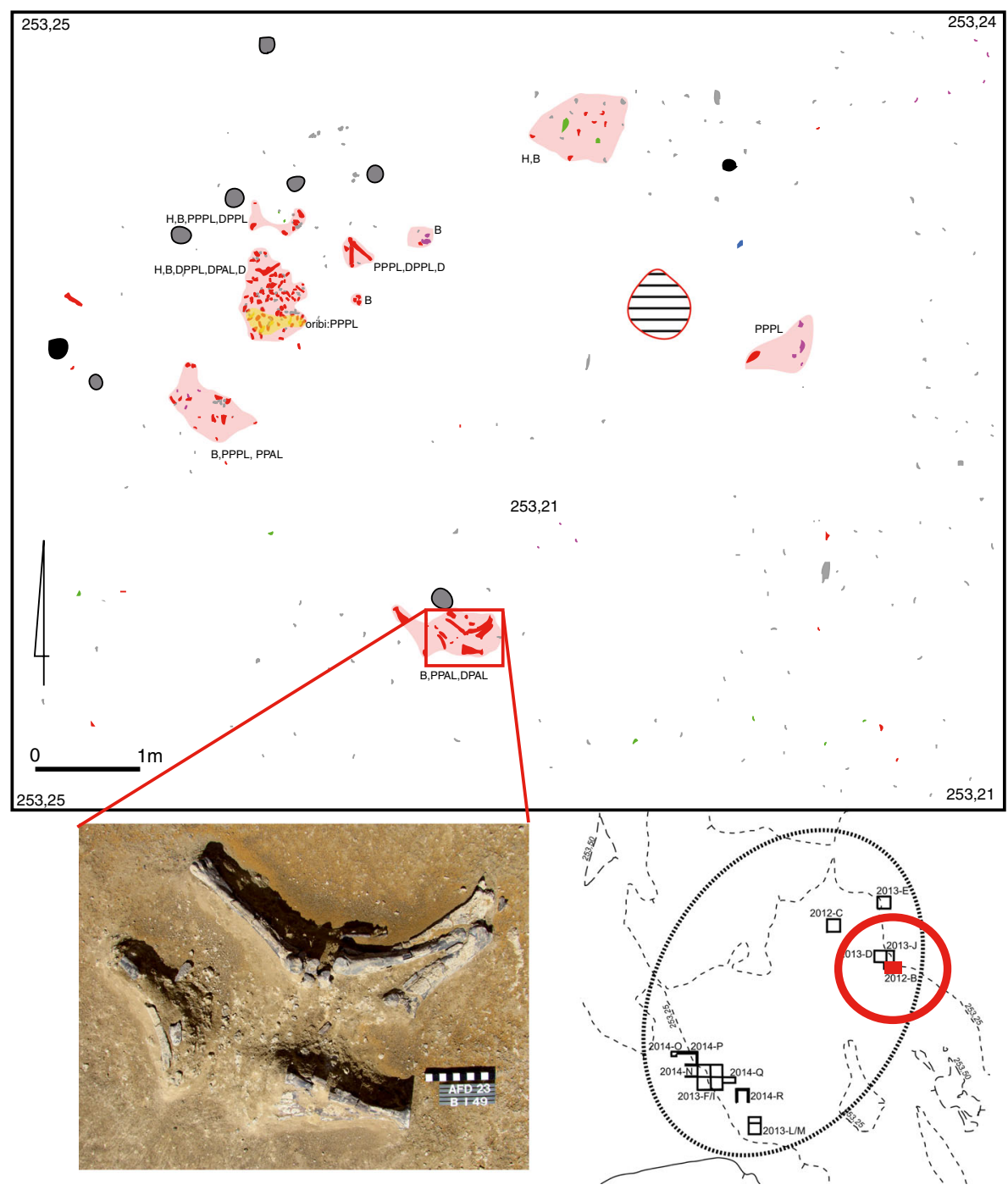

Fig. 3 Excavated parts of Affad 23 site (northern area-trench 2012/B). Location of features and animal bones clusters (Kobus sp.-red; Ourebia ourebi-yellow, Madoqua saltiana - green) with the carcass parts indications ( $H$ head, $B$ body, $P P A L$ proximal part of

as the latest evidence of Middle Stone Age (MSA) in northeastern Africa.

Similar results were obtained for Affad 111, located $1.5 \mathrm{~km}$ to the northeast, at the alluvial plain margin. A sand unit related to the occupation episode contained both Levallois tradition lithics and animal bones, and was dated to $16.0 \pm 1.92 \mathrm{ka}$ (UJK-OSL-38). Also, another site's substrate, Affad 105, with elephant bones found with a single Levallois artefact, produced a similar date $(15.7 \pm 1.73 \mathrm{ka}$, UJK-OSL-40). Basing on previously presented estimates, it should be assumed that other locations with Levallois artefacts and mineralised animal remains at the same anterior limb, $D P A L$ distal part of anterior limb, $P P P L$ proximal part of posterior limb, $D P P L$ distal part of posterior limb, $D$ digits). (Image in full colour online)

elevation, e.g., Affad 110, came from the same temporal horizon. As to the last site, mineralised bone fragments were recently dispersed toward the southwest over the surface of truncated geological units, comparable to Affad 23 stratigraphy (Fig. 6).

\section{Material}

The animal bone found at the Terminal Pleistocene sites in Affad is heavily mineralised. Laboratory tests have revealed the absence of collagen, which prevents the dating 


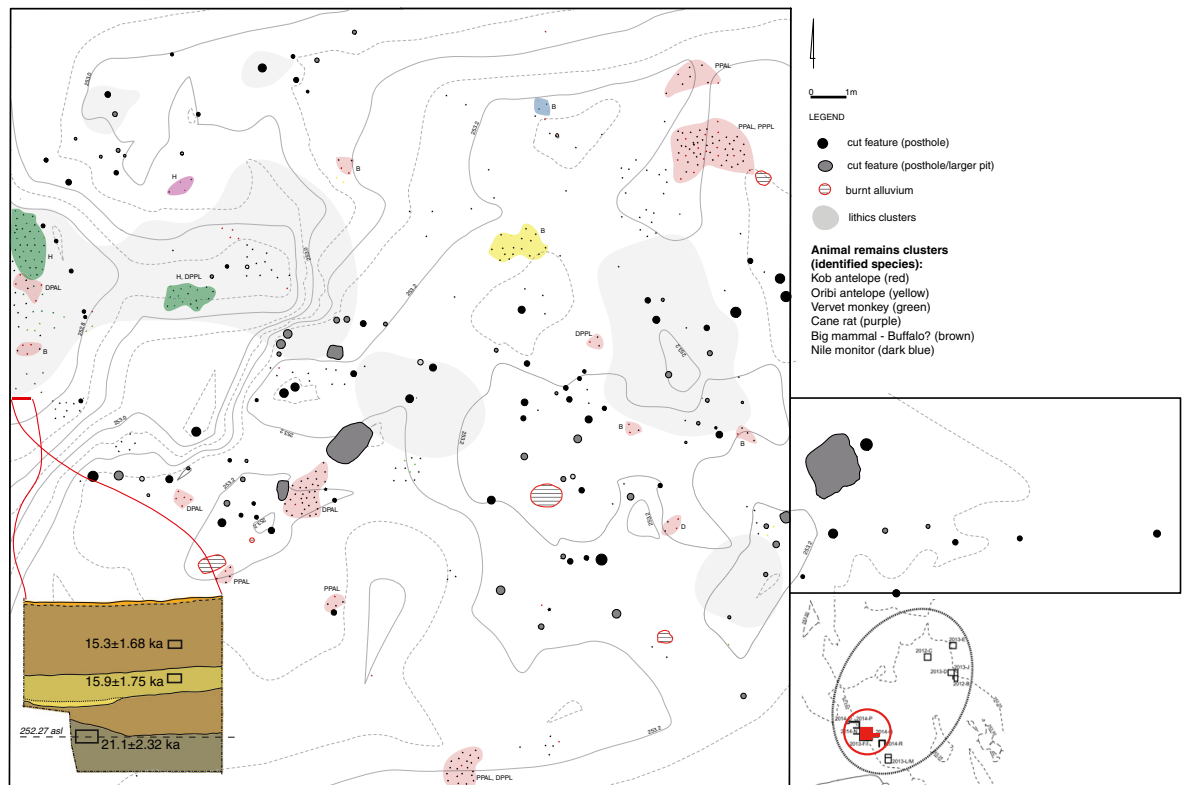

Fig. 4 Excavated parts of Affad 23 site (southwestern area - trench 2013/F-I, Q). Location of features and animal bones clusters (Kobus sp.-red; Ourebia ourebi-yellow, Chlorocebus sp.-green, Thryonomys swinderianus-purple, Varanus

of organic substances by using AMS C14 methods. Attempts were made to date the carbonate fraction; considering trace amounts of carbon $(0.1 \% \mathrm{~N} ; 2.8 \% \mathrm{C} ; 0.04 \mathrm{mg}$ C), the net result $(9570 \pm 150$ uncal bp, Poz-61344) should be regarded as highly uncertain due to the possibility of contamination (T. Goslar, director, AMS radiocarbon laboratory, personal communication). The colour of the animal bones varied from black to dark grey to light brown. Remains uncovered in the underground sediments were marked by a lighter tint and an evident tendency to crumble, while the preserved teeth resemble their natural colour. Remarkably, an occasionally quite thick and irremovable layer of gypsum crust covering the bones (notably those retrieved from the deeper sediments) impeded their identification. Notwithstanding the mineralisation, the state of preservation of the diagnostic features of the osteological material from Affad was excellent, as evidenced by the very high percentage of remains identified (NISP) in terms of species and anatomy in relation to other Pleistocene assemblages (not exceeding $10 \%$-e.g., Gautier 1968, 1987; Chaix et al. 2000; Gautier et al. 2012), namely $24.2 \%$ (Table 1).

The area of Affad yielded a total of 6102 animal remains. Excavations at Affad 23 produced a total of 3864 animal bones; at Affad 110, 1197 bones; and at Affad 111242 and 196 remains in locations a and b, respectively. Surface niloticus - blue) with the carcass parts indications ( $H$ head, $B$ body, PPAL proximal part of anterior limb, DPAL distal part of anterior limb, $P P P L$ proximal part of posterior limb, $D P P L$ distal part of posterior limb, $D$ digits). (Image in full colour online)

survey at further sites yielded another 603 mineralised fragments of animal bone in total.

All of the animal remains found at Affad were transferred for analysis to the Institute of Archaeology and Ethnology of the Polish Academy of Sciences, Poznań Branch, where they are currently being stored.

\section{Methods}

All of the osteological material discussed here was subject to analysis aimed at the most comprehensive taxonomic and anatomical identification of the remains possible. The analysis comprised several stages. In many cases, the condition of the bone material allowed preliminary identification and osteometrical examination only in situ (Fig. 3 shows long bones unearthed; however all had been fragmented). In cases when there were well-preserved diagnostic features, the bones were identified according to taxa and anatomy based on comparable collections and relevant publications (Peters 1986; 1989a; Peters et al. 1997; Plug 2014; Van Neer 1989; Walker 1985). Skeletal remains were also subject to verification and reassessment based on modern comparative collections in Belgium (Royal Belgian Institute of Natural Sciences, Brussels; Palaeontological Research Unit, Ghent University). 


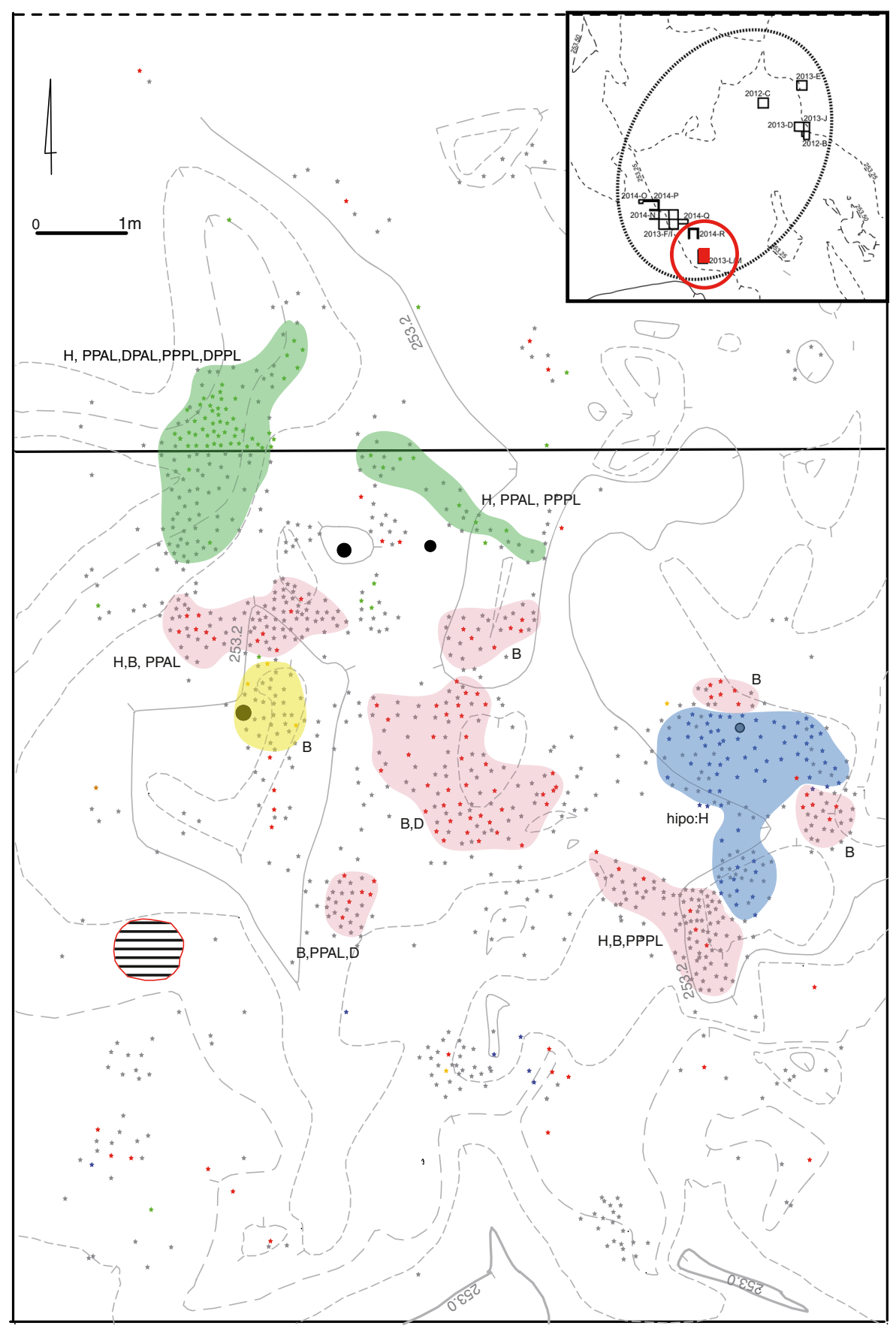

Fig. 5 Excavated parts of Affad 23 site (Southern area - trench 2013/L-M). Location of features and animal bones clusters (Kobus sp.-red; Ourebia ourebi-yellow, Chlorocebus sp.-green, Hippopotamus amphibius—blue) with the carcass

The anatomical origin of a given bone fragment along with the approximate age of the animal, sex and bone metric data were also noted. Remains completely devoid of diagnostic features were counted and recorded in parts indications ( $H$ head, $B$ body, $P P A L$ proximal part of anterior limb, $D P A L$ distal part of anterior limb, $P P P L$ proximal part of posterior limb, $D P P L$ distal part of posterior limb, $D$ digits). (Image in full colour online)

terms of size class and grouped according to relevant contexts.

For the Affad 23 site, the anatomical distributions of the remains of the most often registered animals (Kobus 


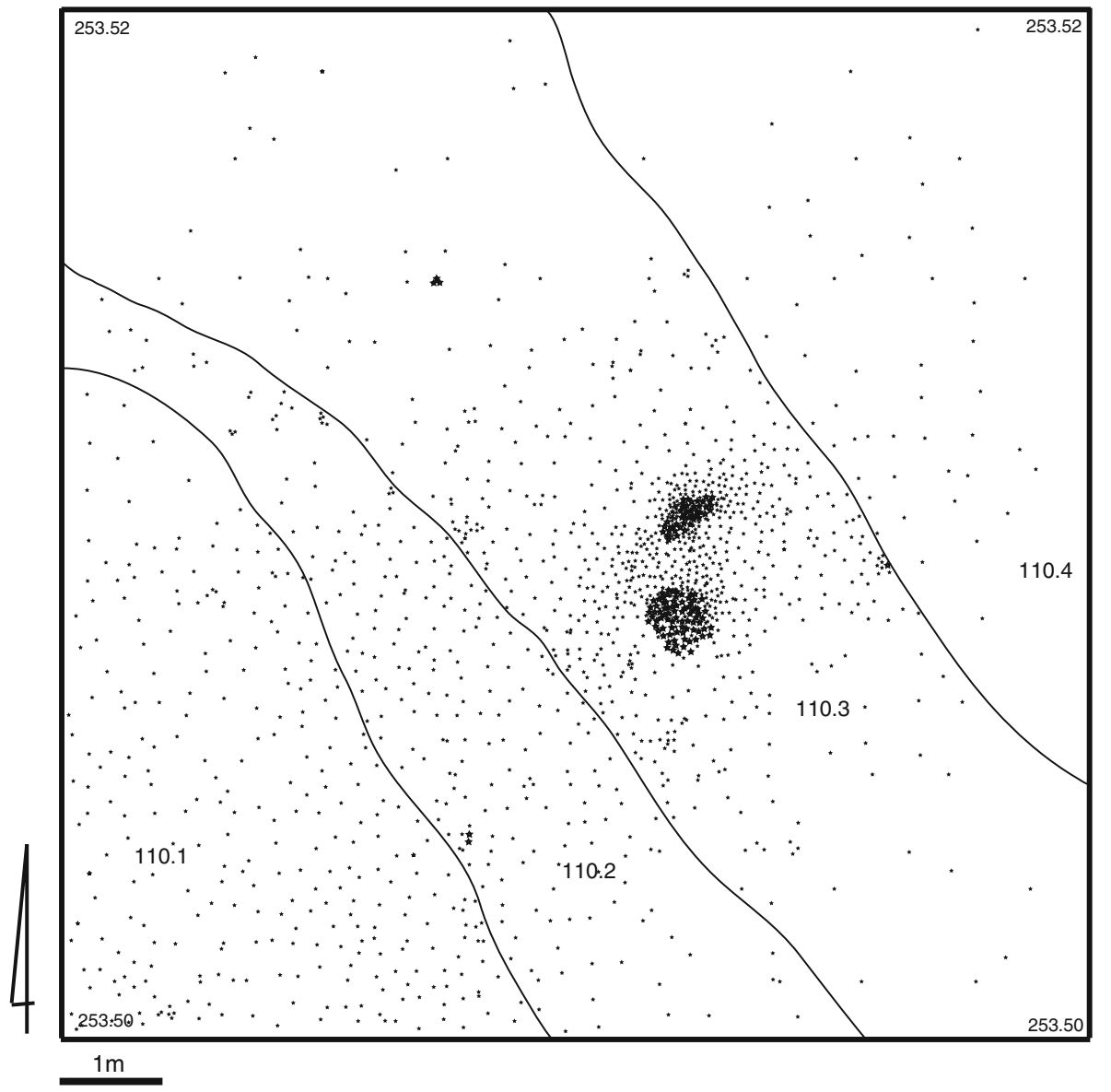

Fig. 6 Excavated part of Affad 110 site. Distribution of animal remains over truncated sediments addressing to Affad 23 stratigraphy (110.1 calcareous silt referring to LGM alluviation, 110.2-

sp., Ourebia ourebi, Madoqua saltiana, Hippopotamus amphibius and Chlorocebus sp.) were also recorded. Based on the anatomical data, the bones of kobus, hippopotamus, and vervets were further analysed in terms of the technological division (after LasotaMoskalewska 2008) of the carcass:

H (head): cranium, dentes, maxilla, mandibula, processus cornualis

Table 1 The proportion of identified and unidentified animal remains from Affad Basin, seasons 2012-2014

\begin{tabular}{lll}
\hline & Number & Percent \\
\hline Identified remains & 1,477 & 24.2 \\
Unidentified remains & 4,625 & 75.8 \\
TOTAL & 6,102 & 100 \\
\hline
\end{tabular}

110.4 following series of sands and silts preceding Holocene sedimentation)

B (body): vertebrae, costae

Proximal part of the anterior limb (PPAL): scapula, humerus, radius, ulna

Distal part of the anterior limb (DPAL): ossa carpi, ossa metacarpi

Proximal part of the posterior limb (PPPL): pelvis, femur, patella, tibia

Distal part of the posterior limb (DPPL): calcaneus, talus, ossa tarsi, ossa metatarsi

$\mathrm{D}$ (digits): phalanx proximalis, phalanx media, phalanx distalis

Given their largest frequency, the remains of kobus were also analysed in terms of anatomical variation at individual locations of the site. The percentage of remains of morphologically immature individuals was also calculated. An osteometrical examination was carried out using standard measurements (von den Driesch 
1976). Osteological materials from both the surface survey and all of the excavated sites were subject to taphonomic observations. We analysed the state of preservation of the remains with respect to the location of their deposition, variability of natural conditions, degree of their impact on the biostratinomic stage as well as identification possibilities (Binford 1981; Grayson 1984, 1989; Lupo et al. 2012; Lyman 1987).

The fish remains were identified by Wim Van Neer (Royal Belgian Institute of Natural Sciences, Brussels) by comparison with the extensive reference collections housed there. The skeletal element and the taxon were recorded for each identifiable bone. When a bone was sufficiently preserved, the corresponding fish size was reconstructed by direct comparison with modern fish of known length. This size was expressed as standard length (SL), i.e., the length of the fish from the tip of the snout to the base of the tail.

\section{Analysis of Hunting Strategies and Dietary Variability}

"Prey choice models predict that top ranked prey (those with a higher energetic yield relative to search, pursuit, and handling costs) will always be taken on encounter; if encounter rates with preferred prey decline, hunters are expected to broaden their diets by including more lower-yield resources" (after Clark and Kandel 2013, p. S274; cf. Bird and O'Connell 2006; Kaplan and Hill 1992; Lupo 2007). According to ethnographic and empirical studies, animals of greater body weight preferred to smaller ones in a hunting ranking, and thus they are ranked higher than smaller animals in classical hunting models (Broughton and Grayson 1993; Kelly 1995; Lupo 2007; Lupo and Schmitt 2005). Theories concerning hunting in the MSA contend that a growing interest in hunting small (lower rank) terrestrial animals is a likely indication of the tendency to diversify and expand the diet (Clark and Kandel 2013; Lombard 2012; Lombard and Clark 2008; Marean et al. 2000). It seems, however, that besides the foregoing factors, the choice of hunting strategies is profoundly influenced by other factors such as opportunities, skills and the availability of tools (poisons and traps including). A useful method of using archaeozoological data in the analysis of the hunting model is in examination of the degree of exploration of different size classes of animals registered at the site. In view of the analysis, we compiled a list of all registered species divided into appropriate size classes from the osteological material from Affad (Table 2). Based on the classification used in the analysis of South African
Table 2 Definition of mammals size class categories used in this study (according Brain 1981; Cain 2006; Marean et al. 2000)

\begin{tabular}{llll}
\hline $\begin{array}{l}\text { Size } \\
\text { class }\end{array}$ & & $\begin{array}{l}\text { Approximate } \\
\text { weight }(\mathrm{kg})\end{array}$ & Examples \\
\hline I & Small & $2.7-10$ & dik-dik, vervet, cane rat \\
II & Small-medium & $10-65$ & warthog, oribi, bohor \\
III & Large-medium & $45-270$ & kobus \\
IV & Large & $300-950$ & buffalo, giraffe \\
V & Mega-fauna & $>950$ & hippopotamus, elephant \\
\hline
\end{tabular}

assemblages, the table was fittingly adapted to the fauna inhabiting northeastern Africa. This method has been successfully and widely employed in studies on MSA hunting strategies (cf. Thompson 2010; Thompson and Henshilwood 2011; Clark and Kandel 2013). Given the absence of remains of invertebrates or birds as well as trace amounts of bones of reptiles and fishes as recorded at Affad 23 , the table is limited only to mammals.

\section{Results of the Research}

\section{Survey Collections}

The surface survey in the area of the Affad Basin identified 11 sites comprising animal remains deposited in the contexts of MSA lithic artefacts. For the purpose of assessing the sites in terms of their function, we collected 603 osteological remains (Table 3). Mammal remains of undetermined species origin were classified into eight taxonomic groups; the ninth group comprised the fish remains. The largest group of remains collected during the surface survey comprised bone fragments of the largest mammals, i.e., elephant and hippopotamus. The finding of elephant bones is related exclusively to site Affad 105, which was most probably a "killing/scavenging site," as indicated by the presence of both animal remains (the presence of bones of exclusively one species) and a few Levallois tools only. The surfaces of the other sites also yielded numerous skeletal fragments and the teeth of hippopotamus along with the bones of oribi antelope. Ruminants were additionally represented by kobus, giraffe and bohor. A single bone of vervet was also found, and the Nile monitor was the only representative of reptiles.

The faunal collection of the Affad surface finds also yielded 99 identifiable fish bones from five different taxa (Table 3). The majority of the remains came from catfish 
Table 3 Frequency and percentage of species registered in the Affad Basin during the surface survey 2012-2014 (collection not involving sieving)

\begin{tabular}{lll}
\hline Species & Number & Percent \\
\hline Vervet (Chlorocebus sp.) & 1 & 0.4 \\
Elephant (Loxodontia africana) & 39 & 17.1 \\
Hippo (Hippopotamus amphibius) & 31 & 13.6 \\
Oribi (Ourebia ourebi) & 31 & 13.6 \\
Bohor (Redunca redunca) & 2 & 0.9 \\
Kobus antelope (Kobus sp.) & 16 & 7.0 \\
Giraffe (Giraffa camelopardalis) & 3 & 1.3 \\
Nile monitor (Varanus niloticus) & 6 & 2.6 \\
Clariidae & 92 & 40.4 \\
Bagrus sp. & 2 & 0.9 \\
Synodontis sp. & 3 & 1.3 \\
Cyprinidae & 1 & 0.4 \\
Tilapiini & 1 & 0.4 \\
NISP & 228 & $100 / 37.8$ \\
Mega-fauna & 101 & 26.9 \\
Large-size bovid & 2 & 0.5 \\
Middle-size bovid & 7 & 3.1 \\
Small-size bovid & 2 & 0.5 \\
Large-size mammal & 78 & 20.8 \\
Middle-size mammal & 38 & 10.1 \\
Small-size mammal & 30 & 8.0 \\
Mammal & 116 & 30.9 \\
Fish & 1 & 0.3 \\
Unidentified & 603 \\
Total & & 62.2 \\
\hline & 100 \\
\hline
\end{tabular}

belonging to the family Clariidae. These were found on all but one of the sites where fish occurred. Two genera, namely Clarias and Heterobranchus, are known from the Sudanese Nile but no diagnostic elements were found among the remains that would have allowed identification of which one occurred at the site. Most of the clariid remains were from very large individuals, around $100 \mathrm{~cm}$ SL up to $110-120 \mathrm{~cm} \mathrm{SL}$ ). The smallest individuals among these catfish measured 50-60 cm SL. Another catfish found at Affad was Bagrus sp. but it was not possible to determine whether the remains belonged to Bagrus docmak or Bagrus bajad; both species occur in the Nile. The two finds are precaudal vertebrae from fish measuring 50-60 cm SL (in AFD84) and 80-90 cm SL (in AFD113). The third catfish found at the Affad sites belongs to the genus Synodontis sp. and again could not be identified to species. A skull roof fragment, found in AFD103, is from a fish measuring 25$30 \mathrm{~cm} \mathrm{SL}$, whereas the two fin spines collected at AFD120 fall in the range of $25-35 \mathrm{~cm}$ SL. The family of carps (Cyprinidae) is represented by a single vertebra of a fish measuring $40-50 \mathrm{~cm} \mathrm{SL}$; in the Sudanese Nile, only Barbus bynni and the four Labeo species attain such sizes.

\section{Excavated Contexts-Species}

A cluster of bone fragments from Affad 110 of one species (Table 4), presumably one individual, suggests its interpretation as a killing or scavenging site, with initial division of the African buffalo carcass plausible. Excavations at the area produced scattered bones from different parts of the skeleton. Several of the long bones (radius, tibia) were characterised by an incomplete process of fusion of epiphyses to diaphyses. The size of the bones and a few metric data indicate that the individual whose remains were recorded at site Affad 110 was at sub-adult age.

The remains of the vervet, hippopotamus and monitor were recorded in assemblages from Affad 23 and Affad 111a. Only Affad 23 produced the bone fragments and teeth of the cane rat, dik-dik, oribi and kobus. Species recorded so far at Affad 111 only include the warthog and crocodile (Table 5).

Excavation of the principal site Affad 23 produced a total of 3864 fragments of animal bone during the 20122014 research. The anatomical origin and species were accurately identified for 985 bones (NISP $=25.5 \%$ ) (Table 6). Representing different size classes yet markedly dominated by one (the ruminants of medium-large size: class III), artiodactyls were the main group of animals identified (Table 7). In total, the remains of seven species of mammals and one species of reptiles were identified at Affad 23. Unspecified remains were grouped according to

Table 4 Frequency and percentage of species registered at site Affad 110

\begin{tabular}{lll}
\hline Species & Number & Percent \\
\hline African buffalo (Syncerus caffer) & 106 & \\
NISP & 106 & 8.9 \\
Large-size bovid & 89 & \\
Large-size mammal & 615 & \\
Mammal & 387 & \\
Unidentified & 1091 & 91.1 \\
Total & 1,197 & 100 \\
\hline
\end{tabular}


Table 5 Frequency and percentage of species registered at site Affad 111a and 111b

\begin{tabular}{|c|c|c|c|c|}
\hline \multirow[b]{2}{*}{ Species } & \multicolumn{2}{|c|}{ AFD 111a } & \multicolumn{2}{|c|}{ AFD 111b } \\
\hline & Number & Percent & Number & Percent \\
\hline Buffalo (Syncerus caffer) & 5 & & 0 & \\
\hline Vervet (Chlorocebus sp.) & 3 & & 0 & \\
\hline Warthog (Phacochoerus africanus) & 1 & & 0 & \\
\hline Hippo (Hippopotamus amphibius) & 1 & & 0 & \\
\hline Nile monitor (Varanus niloticus) & 1 & & 0 & \\
\hline Crocodile (Crocodylus niloticus) & 0 & & 142 & \\
\hline Clariidae & 1 & & 2 & \\
\hline Cyprinidae & 1 & & 0 & \\
\hline Tilapiini & 1 & & 0 & \\
\hline NISP & 14 & 5.8 & 144 & 73.5 \\
\hline Mega-fauna & 16 & & 0 & \\
\hline Large-size antelope & 7 & & 0 & \\
\hline Middle-size bovid & 99 & & 0 & \\
\hline Small-size bovid & 2 & & 0 & \\
\hline Large-size mammal & 49 & & 0 & \\
\hline Middle-size mammal & 25 & & 0 & \\
\hline Small-size mammal & 2 & & 0 & \\
\hline Mammal & 28 & & 0 & \\
\hline Reptile & 0 & & 48 & \\
\hline Unidentified & 228 & 94.2 & 52 & 26.5 \\
\hline Total & 242 & 100 & 196 & 100 \\
\hline
\end{tabular}

seven categories by approximating their taxonomic origin. Assemblages from Affad 23 were evidently dominated by the remains of the kobus, and a group of unspecified bones by a middle-sized bovid and a middle-sized mammal.

The complete list of species recorded in the Affad Basin contains 11 taxa of mammals, 2 reptiles and 5 fishes. Some of them were recorded exclusively on the present surface. However, the most valuable for the description of the human settlement environment as well as the hunting strategies were remains embedded in the stratified sediments of Affad 23. The behaviour of these most frequently recorded species provided the basic data for further studies.

\section{Vervet (Chlorocebus sp.)}

In total, 126 elements of the skeleton of a primate, a vervet, were identified at Affad 23, which accounted for $12.8 \%$ of the materials in terms of taxonomy and anatomy (Fig. 7). Remains of the vervets were discovered in the sediments of two locations: in the ancient ground depression recorded in the northwest part of trenches 2013/F-I and in the southern location situated approx. $50 \mathrm{~m}$ southeast (Table 6; Figs. 4 and 5).

The maximal length of the vervet is $100-130 \mathrm{~cm}$ for males and $95-110 \mathrm{~cm}$ for females. Males weigh from 4 to $8 \mathrm{~kg}$ (average $5.5 \mathrm{~kg}$ ), while females weigh $3.5-5 \mathrm{~kg}$ (average $4 \mathrm{~kg}$ ). Inhabiting a considerable part of subSaharan Africa, vervet are among the most common monkeys in Africa (Nowak 1999; Wolfheim 1983); they are absent only from the desert, high forest and open grassland. They occupy extremely varied habitats, the most important requirement being close proximity to water and trees, necessary for spending the night. For this reason, vervets are particularly common in riparian forests bordering the savanna. They live in groups of up to 20 or more individuals, but most groups tend to be smaller.

\section{Cane Rat (Thryonomys swinderianus)}

The remains of this animal were recorded only in two locations in the area identified as a Terminal Pleistocene 
Table 6 Frequency and percentage of species registered at site Affad 23

\begin{tabular}{|c|c|c|}
\hline Species & Number & Percent \\
\hline \multicolumn{3}{|l|}{ Primates } \\
\hline Vervet (Chlorocebus sp.) & 126 & 12.8 \\
\hline \multicolumn{3}{|l|}{ Rodentia } \\
\hline Cane rat (Thryonomys swinderianus) & 14 & 1.4 \\
\hline \multicolumn{3}{|l|}{ Artiodactyla } \\
\hline Hippopotamus (Hippopotamus amphibius) & 186 & 18.9 \\
\hline Salt's dikdik (Madoqua saltiana) & 12 & 1.2 \\
\hline Oribi (Ourebia ourebi) & 15 & 1.5 \\
\hline Bohor (Redunca redunca) & 6 & 0.6 \\
\hline Kobus antelope (Kobus sp.) & 618 & 62.7 \\
\hline African Buffalo (Syncerus caffer) & 3 & 0.3 \\
\hline \multicolumn{3}{|l|}{ Reptilia } \\
\hline Nile monitor (Varanus niloticus) & 4 & 0.4 \\
\hline \multicolumn{3}{|l|}{ Fish } \\
\hline Clariidae & 1 & 0.1 \\
\hline NISP & 985 & $100 / 25.5$ \\
\hline Mega-fauna & 60 & 6.8 \\
\hline Large-size bovid & 8 & 0.3 \\
\hline Middle-size bovid & 159 & 5.5 \\
\hline Large-size mammal & 102 & 3.5 \\
\hline Middle-size mammal & 312 & 10.8 \\
\hline Small-size mammal & 155 & 5.4 \\
\hline Mammal & 2,083 & 72.4 \\
\hline Unidentified bones & 2,879 & 74.5 \\
\hline Total & 3.864 & 100 \\
\hline
\end{tabular}

camp (trench 2013/I), in small clusters containing mainly fragments of the skull and teeth (Figs. 4 and 8). The cane rat is a rodent living throughout the area south of the Sahara, and is today bred for consumption. These large rodents, measuring from 35 to $60 \mathrm{~cm}$ in length, can weigh up to $10 \mathrm{~kg}$ (MacDonald 1984) in their natural

Table 7 Percentage of remains according to size classes of species registered at Affad 23

\begin{tabular}{lll}
\hline Size class & & Percent \\
\hline I & Small & 8.6 \\
II & Medium-small & 9.8 \\
III & Medium-large & 61.3 \\
IV & Large & 6.4 \\
V & Mega-fauna & 13.9 \\
\hline
\end{tabular}

environment. Cane rats inhabit wetlands along the banks of rivers and lakes. They are herbivores.

\section{Hippopotamus (H. amphibius)}

A total of 186 skeletal fragments were identified (Fig. 9) as belonging to this animal, plus 60 remains which most likely came from a hippopotamus. Among the identified bones, the percentage of hippopotamus remains accounted for $18.9 \%$ (Table 6). It is worth noting that the bone fragments of hippopotamus deposited in the sediment were recorded in one large cluster, scattered over the southern area - trench 2013/M (Fig. 5).

The hippopotamus is one of the largest mammals in the world today, but unlike other animals of African mega-fauna, it has adapted to a semiaquatic lifestyle in freshwater lakes and rivers. Its total body length ranges from 3.4 to $4.2 \mathrm{~m}$, and adults average $1.5 \mathrm{~m}$ at the shoulder. Males weigh from 1000 to $2000 \mathrm{~kg}$, while females weigh $1000-1700 \mathrm{~kg}$. Their primary requirement is sufficient water to allow for complete submergence and they show preference for permanent waters with sandy substrates. Access to adequate grazing is also essential, yet the animals will move several kilometres away from water bodies to reach suitable feeding areas. They spend most of the daylight hours in the water, but emerge frequently to bask on sand and mud banks and on occasion to feed, particularly during overcast, cool days and in areas where they will not be disturbed (Stuart and Stuart 2006).

\section{Salt's Dik-dik (M. saltiana)}

A few remains of this tiny antelope were found spread in two locations at Affad 23 (northern-trench 2012/B, and southwestern-2013/I). Salt's dik-dik is $37 \mathrm{~cm}$ at shoulder height and weighs $2.7-4 \mathrm{~kg}$. Dik-diks live in relatively dry and arid bush country, preferring areas with Acacia trees. They eat selected species of grasses, but also leaves, pods and flowers knocked down by much larger animals, e.g., elephants, greater kudu and baboons. They are territorial animals that live alone or in larger or smaller herds (Stuart and Stuart 2006).

\section{Oribi (O. ourebi)}

Oribi is the second antelope species in the Affad area in terms of frequency of remains (Table 6). Its bones were recorded at all excavated loci-northern (trench 2012/B 


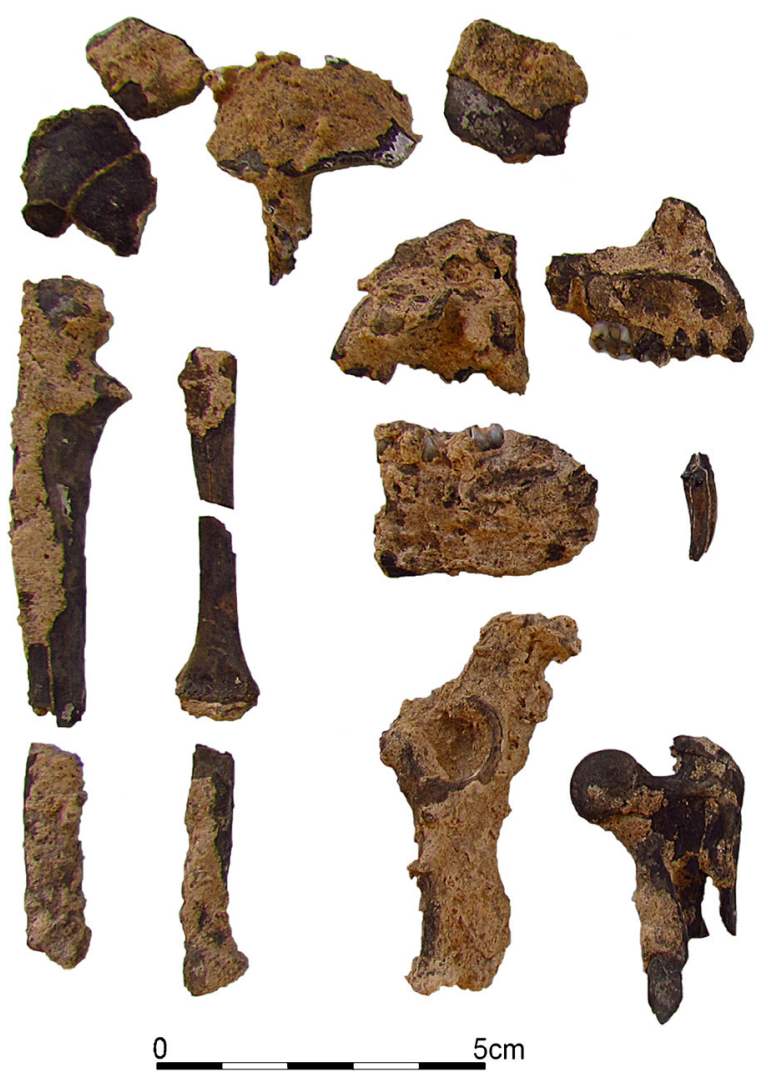

Fig. 7 Fragments of Chlorocebus sp. skeletons-Affad 23, Trench 2013/I

with extension 2013/D), southwestern (2013/I with adjacent sondages 2014/N, 2014/O) and southern (2013/M). With a shoulder height of about $60 \mathrm{~cm}$, oribi is the largest of the "small" antelopes. It weighs from 14-20 kg and its small horns average $10 \mathrm{~cm}$ (Stuart and Stuart 2006). Oribi live on their own, in pairs or in small groups (a male with two or more females). These small
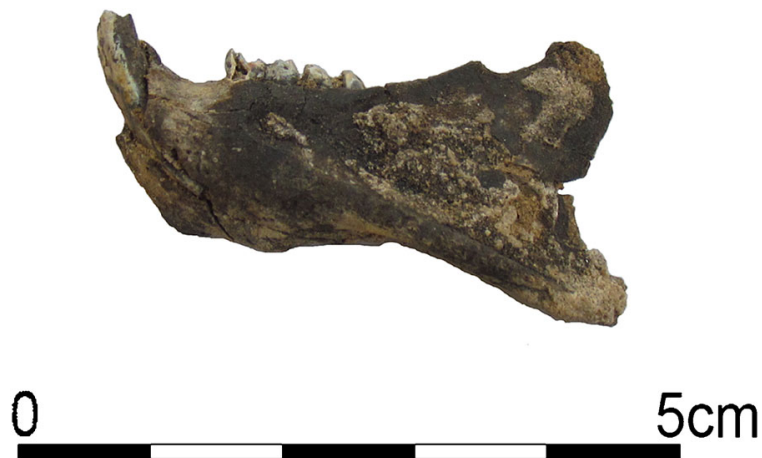

Fig. 8 Mandible of Thryonomys swinderianus - Affad 23, Trench 2013/I antelopes typically inhabit open grasslands or thinly bushed country. Oribi prefer a short grass habitat on which to graze which is interspersed with taller grassy patches to provide cover. Their habitat is closely associated with permanent access to water.

\section{Bohor Reedbuck (Redunca redunca)}

The Bohor reedbuck is the third most common species of ungulates to be recorded in Affad. Listed in locations analogous to the oribi (trenches 2013/I with adjacent sondages 2014/N, 2014/O and 2013/M), this small antelope exhibits similar evident sexual dimorphism. Males stand $70-90 \mathrm{~cm}$ at the shoulder, while females stand $65-80 \mathrm{~cm}$ at shoulder height. Adult males weigh $45-65 \mathrm{~kg}$ and females weigh $35-55 \mathrm{~kg}$. Bohor live either alone or in large herds. They prefer grass with high protein and low fibre content and modify their diet in the dry season. The bohor antelope is dependent on the presence of water, and its typical habitat is closely tied to river floodplains, reed beds as well as seasonally flooded grasslands (Stuart and Stuart 2006).

\section{Kobus Antelope (Kobus sp.)}

Present in all locations at Affad 23, the remains of the kobus antelope were marked by the highest frequency. The site yielded a total of 618 bones of this animal with preserved diagnostic features. In addition, 159 bones were categorised as middlesized bovid (MSB) and middle-sized mammal (MSM), and 312 fragments likely related to this antelope (Fig. 10).

The kobus is a medium-sized antelope linked to a specific habitat. In addition to the differences in weight and size, the kobus exhibits dimorphism in the form of horns present only in males and varied coat colour (Stuart and Stuart 2006). The kobus antelopes inhabit swamps, dry and flooded grassy marsh and steppes. The species is known to inhabit short grass, high reed and cane thickets (Falchetti and Mostacci 1993; Mochi and Carter 1971). It lives in harems which consist of a herd of females and one sexually active male. Calves are born during the rainy season and become independent from their mothers between 6 and 8 months of age (Estes et al. 1971; Falchetti and Mostacci 1993; Nowak 1999; Walther and Grzimek 1990). They are attracted to water and wetlands. In the rainy season, the herd 


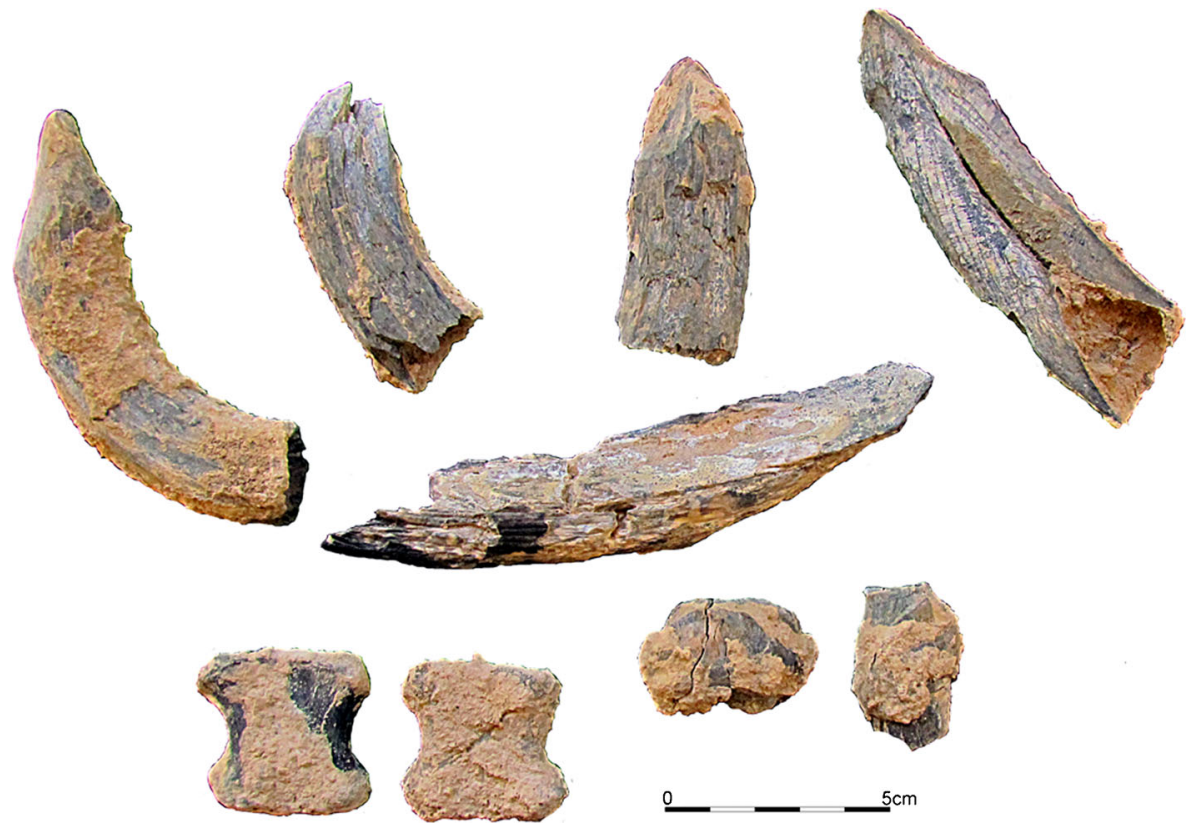

Fig. 9 Hippopotamus amphibius remains - Affad 23, trench 2013/M

scatters over vast expanses of wetlands. In contrast, in the dry season, they gather in herds around the remaining waterholes. They typically feed above the water level, such as on dry banks, sandbanks and islands, and flee to the water when disturbed. Their diet is herbivorous; they eat grass, herbs and water plants (Stuart and Stuart 2006; Walther and Grzimek 1990).

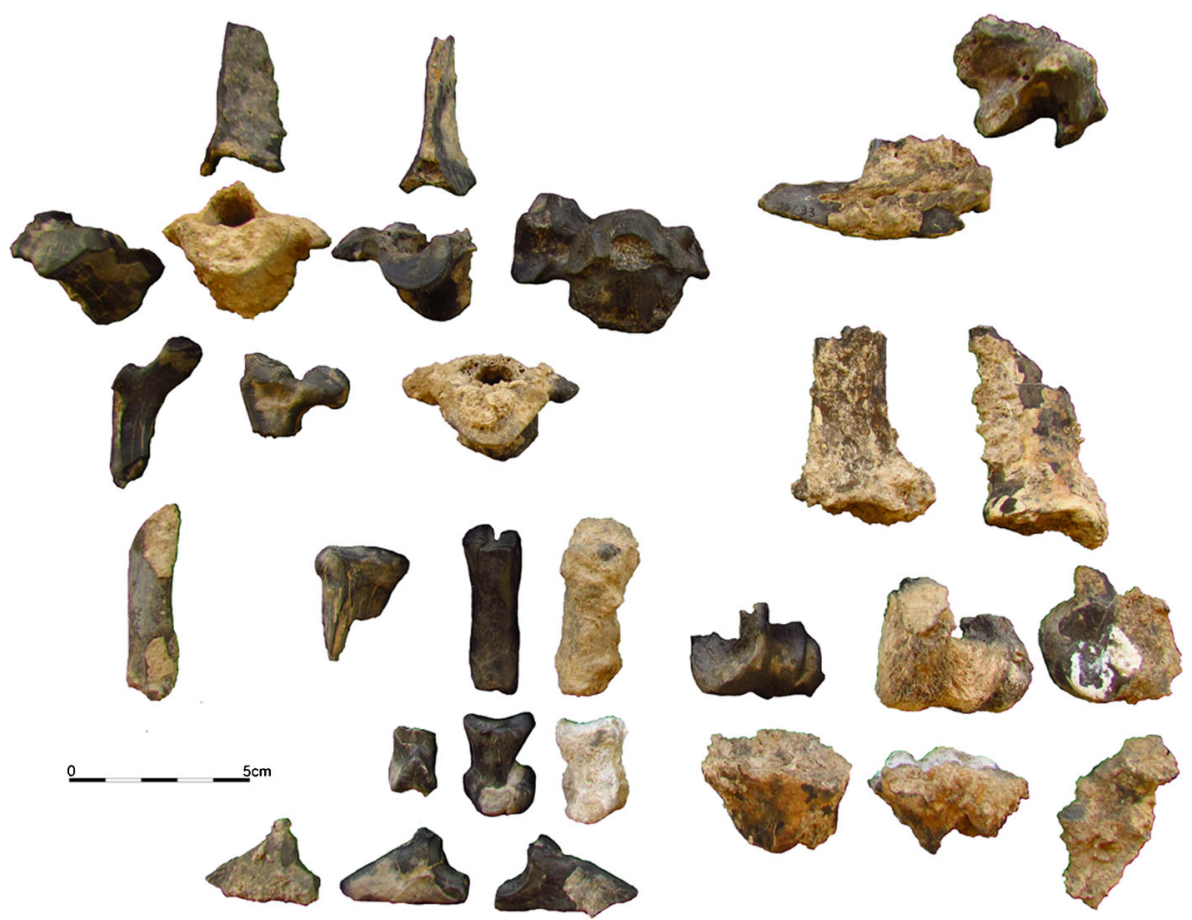

Fig. 10 Remains of Kobus sp.-Affad 23 
African Buffalo (Syncerus caffer)

Remains of one of the greatest African-hoofed mammals, the African buffalo, were found at site Affad 23 in the sediments of two trenches: 2013/M and 2014/P. One of the most dangerous game animals of Africa, the African buffalo stands $1.4 \mathrm{~m}$ at shoulder height; males weight $700 \mathrm{~kg}$, females $500 \mathrm{~kg}$. It prefers open woodland savannah with abundant food and drinking water. Undemanding in terms of diet, the buffalo needs permanent bodies of water. It lives in large herds and, besides humans, is hunted only by lions (Stuart and Stuart 2006).

\section{Spatial Distribution of Animal Remains within Affad 23}

\section{Species}

A total of 892 unearthed osteological fragments, of which $34.3 \%$ have been identified, were found in trench 2012/B, located in the northern part of the site, another location significant in terms of archaeozoological research. The remains came from only three species, and $95.1 \%$ of the bones belonged to only one species - the kobus antelope. So far, trench 2012/B is the only location that yielded complete limb bones arranged in anatomical order along with clusters of vertebrae and ribs (Fig. 3). These were found in the vicinity of five semicircularly arranged postholes and a small hearth.

Trenches 2013/F-I, Q, located in the southwestern part of the study area (the main settlement zone with numerous features, and ground depression filled with stratified deposits), deserve particular attention. While the group of remains was much smaller (329 fragments), as many as seven species were identified. Unlike the previously discussed locations, the bones of the vervet monkey were most frequently represented in this assemblage. The remains of antelopes (kobus, oribi, bohor) were also relatively numerous while other small animal remains (cane rat, Nile monitor) occurred in clear clusters (Fig. 4).

In the context of the total number of animal remains, by far the richest was the southern excavation area (trench 2013/M-L), where a total of 1064 bone fragments were discovered out of which $26.3 \%$ were identified. The assemblage was dominated by the remains of the kobus $(38.6 \%)$ and hippopotamus $(32.5 \%)$. The remains of the vervet monkey constituted a relatively large group of bones (26.8\%), but other species (oribi, buffalo) were represented by single bones. Clear clustering of the particular species remains should be noted (Fig. 5).

\section{Anatomy}

All skeletal elements of the kobus antelope were registered at Affad 23 (Fig. 10). Based on the compiled data, the identified remains of the kobus in general were shown to be dominated by the remains of the "Body" category (30.2\%; Table 8). Bone fragments and teeth from the "Head" group also represented a high percentage, i.e., $20.5 \%$, and corresponded almost exactly to the standard skeleton of a ruminant (Fig. 11). Relatively high was the percentage of bone fragments from the proximal part of the thoracic limbs $(19.2 \%)$. Accounting for a mere $4.7 \%$ of the remains of the kobus uncovered in Affad, phalanges were the least frequently represented.

The northern area of the site (trench 2012/B-Fig. 3) produced evidence of deposition of non-divided limbs (proximal + distal parts). Further clusters contained skeletal elements conforming to consumer-unattractive carcass parts (head fragments, distal parts of limbs and digits), and separately, attractive ones (proximal parts of limbs, vertebrae and ribs). The southwestern area (trenches 2013/F-I, Q, Fig. 4) also produced evidence of attractive and unattractive carcass parts clustering and deposition separately. A notable absence of digits and head elements in the camp area should be underlined. Southern area (trenches 2013/M-L, Fig. 5) showed numerous clusters of vertebrae and proximal parts of limbs, with the unattractive digits and head fragments occurred in trace numbers. Unattractive elements were dispersed over the whole excavated area without notable clustering.

The anatomical distribution of the remains of hippopotamus was found to be entirely dissimilar. Almost all of the recorded remains are fragments of the mandible recorded in a clear ca. $2-\mathrm{m}^{2}$ cluster at the southern part of the site (trench 2013/M). The surface of the site also produced a few dispersed remains from the Body category (Table 8 ).

More than half of the total identified remains of vervet are "Head" fragments. The bones of the proximal part of the limb constitute a relatively large group (PPAL $19.8 \%$, PPPL $13.8 \%$, Table 8). A 
Table 8 Affad 23- the anatomical distribution of remains according to the technological division. Values of a model ruminant skeleton after Lasota-Moskalewska 2008

\begin{tabular}{|c|c|c|c|c|c|c|c|}
\hline & \multicolumn{2}{|c|}{ Kobus } & \multirow{2}{*}{$\begin{array}{l}\text { Model skeleton } \\
\text { of a ruminant } \\
\%\end{array}$} & \multicolumn{2}{|c|}{ Hippo } & \multicolumn{2}{|c|}{ Vervet } \\
\hline & \# & $\%$ & & \# & $\%$ & $\#$ & $\%$ \\
\hline $\mathrm{H}$ & 108 & 20.5 & 20 & 78 & 88.6 & 51 & 50.5 \\
\hline B & 159 & 30.2 & 43 & 9 & 10.2 & 8 & 7.9 \\
\hline PPAL & 101 & 19.2 & 5 & - & & 20 & 19.8 \\
\hline DPAL & 56 & 10.6 & 8 & - & & - & \\
\hline PPPL & 39 & 7.4 & 3 & - & & 14 & 13.9 \\
\hline DPPL & 38 & 7.2 & 7 & - & & 8 & 7.9 \\
\hline D & 25 & 4.8 & 14 & - & & - & \\
\hline
\end{tabular}

$H$ head (cranium, processus cornuales, dentes, maxilla, mandibula); $B$ body (vertebrae, costae); $P P A L$ proximal part of anterior limb (scapula, humerus, radius, ulna); DPAL distal part of anterior limb (ossa carpi; ossa metacarpi); $P P P L$ proximal part of posterior limb (pelvis, femur, patella, tibia); $D P P L$ distal part of posterior limb (ossa tarsi, calcaneus, talus, ossa metatarsi); $D$ digits (phalanx proximalis, phalanx medialis, phalanx distalis)

similar pattern of carcass parts clustering and deposition was recorded both in the southwestern and southern areas.

In the case of cane rat, a major part of the remains are the elements of the Head recorded exclusively in a $1-\mathrm{m}^{2}$ cluster in the southwestern area (trench 2013/I).

The bones of immature individuals were absent only in the case of the vervet. Morphologically immature individuals accounted for $4.4 \%$ of the bones of the kobus and were noticed most in the northern area. It is worth noting that remains of very young animals were not registered; all came from individuals of sub-adult age. Research at
Affad 23 also produced five bones from morphologically immature oribi spread over the whole site surface, as well as two bones from large bovidae (probably buffalo) of sub-adult age, and a fragment of the lower jaw with teeth erupting from a young hippopotamus from the same unspecified context.

Owing to the condition of the remains, we were able to conduct an osteometric examination notably for the kobus antelope, but also for the vervet (Tables 9 and 10), that will serve as raw data for further paleontological studies over temporarily driven changes in animal morphology.

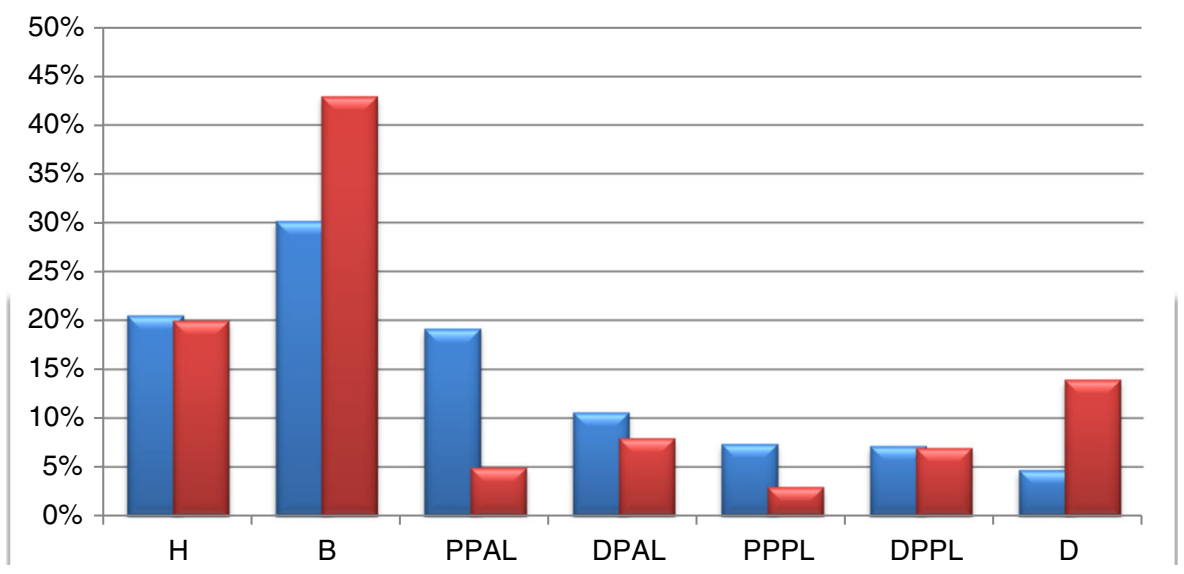

Fig. 11 Frequency of skeletal parts of kob (blue) compared to a model skeleton of ruminants (red). (Image in full colour online) 
Table 9 Osteometric data-Kobus sp., Affad 23 site (standard metrics after Von den Driesch 1976

\begin{tabular}{|c|c|}
\hline Bone & Osteometric data $(\mathrm{mm})$ \\
\hline Scapula & SLC-24.7; 33.0 \\
\hline Humerus & $\begin{array}{l}\text { Bd-42.8; } \\
\text { Bd-42.3; BT-38.7 }\end{array}$ \\
\hline Radius & $\begin{array}{l}\text { GL-190; Bd-39.2; Bp-45.7 } \\
\text { Bd-32.1; 37.6; } 32.0 \\
\text { Bp-42.9; 42.4; } 39.4\end{array}$ \\
\hline O. metacarpi & $\begin{array}{l}\text { GL-185.0; Bp-32.9; Bd-35.6 } \\
\text { Bd-35.4 }\end{array}$ \\
\hline Tibia & Bd-36.3 \\
\hline Talus & $\begin{array}{l}\text { GLI-40.8; GLm-43.6; Bd-25.3 } \\
\text { GLI-38.5; GLm-37.5; Bd-22.0 } \\
\text { GLI-37.6; GLm-36.7; Bd-22.1 } \\
\text { Bd-22.2 }\end{array}$ \\
\hline Patella & GL-39.9 \\
\hline Calcaneus & GL-85.4; 85.4 \\
\hline O. metatarsi & $\begin{array}{l}\text { Bd-37.0; } 28.1 \\
\text { Bd-37.0 }\end{array}$ \\
\hline $\mathrm{Ph}$ proximalis & $\begin{array}{l}\text { GL-47.8; SD-11.6; Bd-13.2; Glpe-45.1 } \\
\text { Bp-16.7; SD-12.0; Bd-14.6; GL-48.8 } \\
\text { Bp-16.5 } \\
\text { Bd-12.8; 12.3; } 14.0\end{array}$ \\
\hline $\mathrm{Ph}$ media & $\begin{array}{l}\text { GL-30.7; Bp-16.8; SD-12.5; Bd-11.9 } \\
\text { GL-26.0; Bp-11.4; Bd-9.7; SD-8.3 } \\
\text { GL-26.9; Bp-14.2; SD-11.8; Bd-13.0 } \\
\text { Bp-13.7 }\end{array}$ \\
\hline $\mathrm{Ph}$. distalis & $\begin{array}{l}\text { DLS-41.4; Ld-38.8; MBS-9.4 } \\
\text { DLS-40.5; Ld-33.5; MBS-10.2 } \\
\text { DLS-43.7; } 42.4 \\
\text { DLS-37.2; Ld-30.6 } \\
\text { DLS-42.6; Ld-38.3 } \\
\text { DLS-41.4; Ld-39.7 } \\
\text { DLS-43.7 } \\
\text { DLS-42.4 } \\
\text { DLS-37.2; Ld-30.6 }\end{array}$ \\
\hline
\end{tabular}

$S L C$ smallest length of the Collum scapulae; $B d$ greatest breadth of the distal end; $G L$ greatest length; $B p$ greatest breadth of the proximal end; $B T$ breadth of the trochlea; $G L I$ greatest length of the lateral half; greatest length of the medial half; $S D$ smallest breadth of the diaphysis; GLpe greatest length of the peripheral half; $D L S$ greatest (diagonal) length of the sole; $L d$ length of the dorsal surface)
Table 10 Osteometric data-Chlorocebus sp., Affad 23 site (abbreviations — see Table 9)

\begin{tabular}{ll}
\hline Bone & Osteometric data $(\mathrm{mm})$ \\
\hline Humerus & Bd-15.4; 13.1 \\
& Bd-12.3; BT-11.6 \\
\hline
\end{tabular}

\section{Discussion}

Taphonomy and Anatomy

Faunal remains from the Affad sites have been taphonomically analysed. However, apart from a single instance of cut marks (Fig. 12) on the vertebral body (Corpus body) of the lumbar vertebra (vertebrae lumbales) of kobus antelope, we recorded no traces of biostratinomic factors. Mineralisation of the remains significantly influenced bone fractures and disabled evaluation of the green-fracture planes. Also, the boneburning assessment was limited due to the same reasons. No sign of post-depositional predator activities was noticed either (Lyman 1994).

The condition of the remains, and consequently, the quality of the data they provided, were critically influenced by the water-related environment. Bone mineralisation was indisputably happening due to the relatively rapid sinking of the animal remains in silts deposited by subsequent phases of the Nile, overflowing its main riverbed. This phenomenon was undoubtedly conducive to protecting the bone material from the impact of climatic conditions and the damaging effects of biological agents (scavengers, mildew, fungi, etc.). Mineralisation of the bones was further enhanced by considerable penetration of the water, which is rich in inorganic compounds in this area. Observations on the anatomical distribution of animal remains from Affad in relation to their state of preservation further indicate the crucial role of the wetland. Macroscopic observation of materials from around the Affad Basin indicate that more mineralised, and thus less brittle, are skeletal elements characterised by relatively thin substantia compacta, i.e., short bones (ossa brevia) or flat bones (ossa plana): skeletal elements of lower bone density (cf. Brain 1981; Gifford-Gonzalez 1989; Lyman 1994; Meadow 1980). Their state of preservation is good, and the change in environmental conditions upon excavation does not exert any destructive effects on them. In contrast, bones characterised by higher density and 


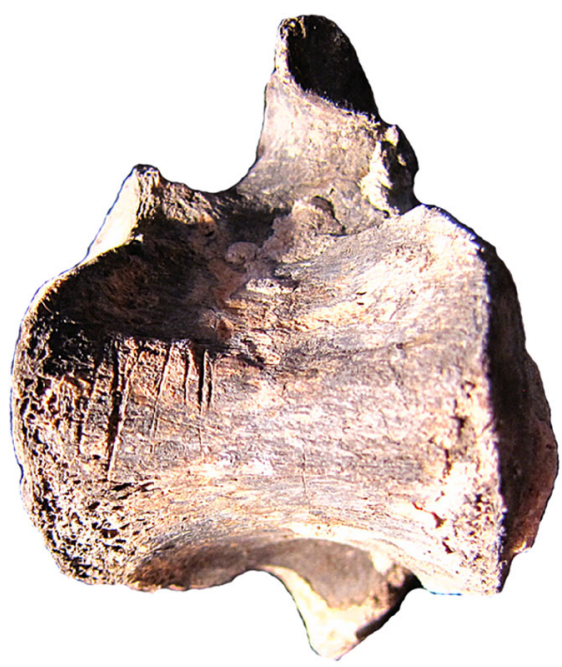

0

Fig. 12 Kobus antelope lumbar vertebrae with cut marks, Affad 23 , trench $2013 / \mathrm{M}$

thicker substantia compacta, i.e., the long bones and teeth, are generally poorly mineralised, and the diaphyses of long bones are particularly susceptible to destruction and complete disintegration. Virtually, no diaphyses of long bones have been registered, notably when it comes to large and great species, contrary to the epiphyses of long bones, including those from young individuals. Complete long bones were recorded only in situ, e.g., in trench 2012/B. The fragments of the diaphyses of long bones are the main component of the unspecified remains. We believe that this observation is of utmost importance for further archaeozoological analysis of remains, which is essential in studying assemblages marked by far-reaching mineralisation.

The well-preserved remains of trench 2012/B, sometimes preserved in anatomical order, also provide data on the methods of treatment of ruminant carcasses by Terminal Pleistocene people. Clusters of vertebrae and ribs were dispersed over a relatively small space, while parts of the skull and teeth were recorded separately. Slightly farther were abandoned large limb fragments: left humerus, radius, ulna, ossa metacarpalia, ossa carpalia; and the right femur, tibia, ossa tarsi, talus, and calcaneus. The method of carcass division suggests that after removing the skin and the head separation, the meat was probably gradually filleted from the bone. It seems that the meat was not divided with the bone. The removal of small fillets of meat may be indicative of further steps in its processing. Given the presence of postholes, i.e., relics of light wooden structures (racks?), it seems highly probable that antelope meat could have been dried (cf. Van Neer et al. 2000). Such methods of processing carcasses do not substantially affect the modification of anatomical distribution since bones do not undergo fragmentation during processing. The anatomical distribution of remains from the archaeological contexts and the natural anatomical distribution of a given species are therefore similar for the northern and southern areas (trenches 2012/B and 2013/M). However, in the area of the camp (trench 2012/F-I, Q), exclusively proximal parts of limbs, vertebrae and ribs were noted, and this could explain the total surplus of these elements.

As noted earlier, the animal remains from Affad are almost devoid of any marks left by tools during the division of the carcass (excepting the single cut mark; Fig. 12). Similarly, there are no remains bearing traces of bone processing as a raw material for tool production. Filleting the meat was a sufficiently effective method of processing the carcasses of antelopes, not to mention much larger animals such as buffalo and hippopotamus, by using relatively small stone tools (less than $10 \mathrm{~cm}$ of cutting edge, and usually less than $5 \mathrm{~cm}$ ). People avoided dividing the bones and joints, which typically leaves traces in the form of cuts and damage on the epiphyses (Cain 2006).

\section{Hunting and fishing strategies}

Kobus antelope was the main species hunted. Its territoriality, grouping in close proximity to bodies of water notably in the dry season, as well as non-aggressive behaviour, made this medium-sized antelope the most optimal hunted species for the Terminal Pleistocene communities from Affad. The remains of smaller animals, and therefore of a lower hunting rank, are a rare occurrence in the Affad materials. It seems that these animals were caught only if the occasion arose (cf. Faith 2011; Stiner et al. 1999); the same pertained to large and dangerous animals (Faith 2008). With its body size larger than that of the kobus, the buffalo is a dangerous animal, hence the choice of the former as the "first rank" species seems to be fully rational. This is another factor pointing to a typical MSA hunting model based on the work of individual hunters or small groups (Dusseldorp 2010; Klein et al. 1991, 2004; Steele and Klein 2009; Stiner and Munro 2002; Weaver et al. 2011). Also, we 
noted no evidence of gathering (and consuming) ostrich eggs nor molluscs, contrary to most early Holocene assemblages (Gautier 1983; Peters 1989b).

Archaeozoological analyses point to the Affad Basin as a seasonal hunting area visited in the dry season, when antelopes (notably kobus) were grouping into large herds and gathering around relatively small waterholes. The evident dominance of the remains of this species suggests focus on hunting. Small camps were set up on the upland area, and sites of processing at least some of the carcasses of the hunted animals were organised in the vicinity (cf. Clark 2011). Two such locations identified at Affad 23, consisting of a camp and a large cluster of bones located at some tens of metres away, are indicative of such a model. While it is difficult to estimate to what extent skills of a group allowed for hunting (or just scavenging) for such large and dangerous animals as the hippopotamus, elephant and buffalo, it is nevertheless unquestionable that only parts of the carcasses of such animals were brought to the camps. The concentration of remains in trench 2013/M produced merely fragments of the skull, jaw and teeth of the hippopotamus, while the remains of a postcranial skeleton were registered on the surface only at a distance of tens of metres.

The fish remains that were found at the Affad sites all came from animals that were sexually mature. The taxa found there were most vulnerable while reproducing, in particular clariid catfish, cyprinids and tilapia, which typically spawn in the shallow waters of the floodplain (Van Neer 2004; Van Neer et al. 1993; Van Neer et al. 2000). It is striking that besides these typical shallowwater species, two other taxa are found (Bagrus sp. and Synodontis sp.) on the surface that are usually considered open-water species, typically confined to the main river. Their remains, and those of Nile perch, are usually not found in Palaeolithic sites, which are believed to be the result of fishing restricted to floodplains. Perhaps at Affad there were places in the river system, with its supposed multi-channel braided morphology (Osypiński et al. in press), where open-water fish were more accessible to humans. If that was the case, this would mean that fish may have also been exploited outside the spawning season. The role of smaller fish which may have been taken from residual pools or other shallow water environments cannot be estimated, as these are entirely absent from the faunal (surfacesic!) collection. However, it is likely that they were exploited, given the ease with which they can be harvested in large quantities in swampy floodplains.

A narrow chronological horizon of the communities functioning at Affad 23 precludes an analysis of the trends or behavioural transformations related to exploitation of the ecosystem. Nonetheless, a consistent picture of the faunal exploitation model and strategies recognisable in Affad correspond well with knowledge of the hunting practices and behaviour of human communities in the Middle Stone Age, crucial for assessing cultural patterns in northeastern Africa in the Terminal Pleistocene.

\section{Ecology and Behaviour}

A list of species recorded during research at the settlement and culturally related to the MSA traditions in Affad seems to produce a very coherent whole in terms of ecology. All of the recorded species so far inhabited either backwater, swampy ecosystems, areas located in the immediate vicinity of bodies of water (kobus antelope, hippopotamus, cane rat, monitor, crocodile), or requiring easy and permanent access to waterholes (vervet, oribi, buffalo, bohor, dik-dik). The behaviour of species recorded in the sediments at the Affad sites suggests that ca. 15,000 years ago this was a backwater area. The banks of bodies of water left by the Nile were covered with reeds and bushes. The whole area can be defined as tree savanna with its abundance of grasses, herbs and shrubs to meet the nutritional needs of diverse ungulates. Without a doubt, this ecosystem was also inhabited by a variety of predators, e.g., lions, cheetahs, hyenas, and wild dogs. However, the Affad materials have not produced the bones of predatory animals, except for the crocodile from Affad 111. The lack of remains of very young antelopes can confirm the hypothesis that human groups occupied the study area essentially in the dry season.

The ecosystem reconstructed on the basis of both geomorphological and archaeozoological data stands in clear opposition to the habitat identified for the functioning of human groups in the Terminal Pleistocene in the area of Lower Nubia. Species identified at sites in southern Egypt corresponded to semi-desert and dry Sahel conditions (Gautier 1968, 1987). By analogy, initially, the ecosystem in which human groups functioned in the Middle Nile Valley was identified accordingly (Chaix et al. 2000; Gautier et al. 2012). Yet the results of the foregoing studies have shown that 
communities inhabiting the Affad Basin at ca. 16-15 ka BP explored an environment of periodically flooded tree savannah. Species listed in Affad correspond to the ecology of central and eastern Sudan during Terminal Pleistocene and early Holocene (Peters 1989b, 1992), but they stand in marked contrast to the contemporaneous environment recorded in Lower Nubia. Besides the classical Levallois stone-processing methods, it is the habitat and hunting strategies identified in our study that point to the "classic" Middle Stone Age behaviour of communities inhabiting Affad (Clark 2011; Gagnon and Chew 2000; Hovers and Belfer-Cohen 2006). With regard to the absolute chronology and state of knowledge regarding the Terminal Pleistocene societies of Lower Nubia, the model was archaic, and comparable only to a much older Khormusan dated generally to MIS4 (Wendorf and Schild 1992).

\section{Conclusions}

Study of the Affad faunal materials, combined with the results of archaeological and geomorphological studies, indicate that hitherto unrecognised communities here functioned in the "classical" Middle Stone Age way, and were true epigones of a world tens of thousands of years older. The results of the archaeozoological analysis helped to determine the environment which served as a habitat both for these communities and for the hunted/ scavenged species. At 16-15 ka BP, the area of Affad acted as a hunting zone in the dry season. While kobus antelope seems to have been of utmost significance for the hunters, their skills made it possible to also exploit both smaller (vervet, cane rat, dik-dik, oribi, reptiles and fishes) and larger animals (buffalo, hippo, elephant). In the vicinity of the seasonal camps the animal carcasses were processed and the meat could be pre-conserved by drying.

The results of the studies on the fauna, ecosystem and hunting strategies of human groups living in the Terminal Pleistocene in the Middle Nile Valley has furnished new proxy data on the complexity of the cultural and ecological situation at that time. The global climate mitigation, which occurred at about $15 \mathrm{ka} \mathrm{BP}$, saw the expansion of the last societies representing late Middle Stone Age behaviour into the area of the southern Dongola Reach, together with the expanding ecosystem of marshy, tree savanna. A total of $500 \mathrm{~km}$ down the Nile, groups representing similar technological traditions (e.g., Sebilian after Schild and Wendorf 2010) met different, more dry environment and welladapted societies with Late Stone Age technology and social organisation. The research results have revealed that still at the end of the Pleistocene, the Middle Nile Valley was occupied by human communities for which a close relationship with a particular habitat and ecosystem had broader evolutionary implications.

Acknowledgments The research project at Affad was financed exclusively by the Polish National Science Centre-grant no. UMO-2011/01/D/HS3/04125. Fieldwork was carried out with the permission and close cooperation of the Sudanese National Corporation for Antiquities and Museums, Khartoum. We would like to thank Professor Wim Van Neer from L'Institut Royal des Sciences Naturelles de Belgique who analysed the fish remains as well as Professor Achilles Gautier for his kind help and comments regarding the species identification in Belgium.

Open Access This article is distributed under the terms of the Creative Commons Attribution 4.0 International License (http:// creativecommons.org/licenses/by/4.0/), which permits unrestricted use, distribution, and reproduction in any medium, provided you give appropriate credit to the original author(s) and the source, provide a link to the Creative Commons license, and indicate if changes were made.

\section{References}

Bate, D. M. A. (1951). The mammals of Singa and Abu Hugar. Fossil Mammals of Africa, 2, 1-28.

Binford, L. R. (1981). Bones. Ancient men and modern myths. New York: Academic.

Bird, D. W., \& O'Connell, J. F. (2006). Behavioural ecology and archaeology. Journal of Archaeological Research, 14, 143188.

Brain, C. K. (1981). The hunters or the hunted? An introduction to African cave taphonomy. Chicago: University of Chicago Press.

Broughton, J. M., \& Grayson, D. K. (1993). Diet breadth, adaptive change and the White Mountain fauna. Journal of Archaeological Science, 20, 331-336.

Cain, C. R. (2006). Human activity suggested by the taphonomy of $60 \mathrm{ka}$ and $50 \mathrm{ka}$ faunal remains from Sibudu Cave. Southern African Humanities, 18, 241-260.

Chaix, L., Faure, M., Guérin, C., \& Honegger, M. (2000). Kaddanarti, a Lower Pleistocene assemblage from Northern Sudan. In L. Krzyżaniak, K. Kroeper, \& M. Kobusiewicz (Eds.), Recent research into the Stone Age of northeastern Africa (pp. 33-46). Poznan: Poznań Archaeological Museum.

Clark, J. L. (2011). The evolution of human culture during the later Pleistocene: using fauna to test models on the emergence and nature of "modern" human behaviour. Journal of Anthropological Archaeology, 30, 273-291. 
Clark, J. L., \& Kandel, A. W. (2013). The evolutionary implications of variation in human hunting strategies and diet breadth during the Middle Stone Age of Southern Africa. Current Anthropology, 54(S8), 269-287.

von den Driesch, A. (1976). A guide to the measurement of animal bones from Archaeological sites, Peabody Museum Bulletins, 1. Cambridge: Peabody Museum.

Dusseldorp, G. L. (2010). Prey choice during the South African Middle Stone Age: Avoiding dangerous prey or maximizing returns? African Archaeological Review, 27, 107-133.

Estes, R., Geist, F., \& Walther, F. (1971). Social organization of the African Bovidae. In F. Geist \& F. Walther (Eds.), The behaviour of ungulates and its relation to management (pp. 166205). Morges: Unwin Brothers Unlimited.

Faith, J. T. (2008). Eland, buffalo, and wild pigs: Were Middle Stone Age humans ineffective hunters? Journal of Human Evolution, 55, 24-36.

Faith, J. T. (2011). Ungulate biogeography, statistical methods, and the proficiency of Middle Stone Age hunters. Journal of Human Evolution, 60, 315-317.

Falchetti, E., \& Mostacci, B. (1993). The Nile lechwe: PVA factors and guidelines to captive management. International Zoo Yearbook, 32(0074-9664), 60-69.

Gagnon, M., \& Chew, A. E. (2000). Dietary preferences in extant African Bovidae. Journal of Mammalogy, 81, 490-511.

Gautier, A. (1968). Mammalian remains of the northern Sudan and southern Egypt. In F. Wendorf(Ed.), The prehistory of Nubia (Vol. I, pp. 80-99). Dallas: Fort Burgwin Research Center \& Southern Methodist University.

Gautier, A. (1983). Animal life along the prehistoric Nile: The evidence from Saggai 1 and Geili (Sudan). Origini, 13, 50115.

Gautier, A. (1987). Fishing, fowling and hunting in late palaeolithic times in the Nile valley in Upper Egypt. Palaeoecology of Africa, 18, 429-440.

Gautier, A., Makowiecki, D., Paner, H., \& Van Neer, W. (2012). Palaeolithic big game hunting at HP766 in Wadi Umm Rahau, Northern Sudan. Journal of African Archaeology, $10(2), 165-174$.

Gifford-Gonzalez, D. (1989). Ethnographic analogues for interpreting modified bones: Some cases from East Africa. In R. Bonnichsen \& M. H. Sorg (Eds.), Bone modification (pp. 179-264). Orono: Center for the Study of the First Americans, University of Maine.

Grayson, D. K. (1984). Quantitative zooarchaeology. Topics in the analysis of archaeological faunas. New York: Academic.

Grayson, D. K. (1989). Bone transport, bone destruction, and reverse utility curves. Journal of Archaeological Science, 16, 643-652.

Hovers, E., \& Belfer-Cohen, A. (2006). "Now you see it, now you don't"-Modern human behaviour in the Middle Palaeolithic. In E. Hovers \& S. L. Kuhn (Eds.), Transitions before the transition: Evolution and stability in the Middle Palaeolithic and Middle Stone Age (pp. 295-304). New York: Springer.

Kalicki, T., \& Olszak, I. (2016). OSL methodology (supplemental information). In P. Osypinski et al. (Eds.), Terminal Pleistocene habitation structures and riverine palaeoenvironments of the Middle Nile Valley: Evidence from the settlement site Affad 23, Sudan. Antiquity 90 (352), doi:10.15184/aqy.2016.110.
Kaplan, H., \& Hill, K. (1992). The evolutionary ecology of food acquisition. In E. A. Smith \& B. Winterhalder (Eds.), Evolutionary ecology and human behaviour (pp. 167-201). Hawthorne: Aldine.

Kelly, R. L. (1995). The foraging spectrum: Diversity in huntergatherer lifeways. Washington, DC: Smithsonian Institution.

Klein, R. G., Avery, G., Cruz-Uribe, K., Halkett, D., Parkington, J. E., Steele, T., Volman, T. P., \& Yates, R. (2004). The Ysterfontein 1 Middle Stone Age site, South Africa, and early human exploitation of coastal resources. Proceedings of the National Academy of Sciences of the United States of America, 101, 5708-5715.

Klein, R. G., Cruz-Uribe, K., \& Beaumont, P. B. (1991). Environmental, ecological, and paleoanthropological implications of the late Pleistocene mammalian fauna from Equus Cave, Northern Cape Province, South Africa. Quaternary Research, 36, 94-119.

Lasota-Moskalewska, A. (2008). Archeozoologia. Warszawa: Ssaki.

Lombard, M. (2012). Thinking through the Middle Stone Age of subSaharan Africa. Quaternary International, 270, 140-155.

Lombard, M., \& Clark, J. L. (2008). Variability and change in Middle Stone Age hunting behavior: Aspects from the lithic and faunal records. In S. Badenhorst, P. Mitchell, \& J. C. Driver (Eds.), Animals and people: Archaeozoological papers in honour of Ina Plug (pp. 46-56). British Archaeological Reports International Series 1849. Oxford: Archaeopress.

Lupo, K. D. (2007). Evolutionary foraging models in zooarchaeological analysis: Recent applications and future challenges. Journal of Archaeological Research, 15, 143-189.

Lupo, K. D., Fancher, J. M., \& Schmitt, D. N. (2012). The taphonomy of resource intensification: Zooarchaeological implications of resource scarcity among Bofi and Aka forest foragers. Journal of Archaeological Method and Theory, 20, 420-447.

Lupo, K. D., \& Schmitt, D. N. (2005). Small prey hunting technology and zooarchaeological measures of taxonomic diversity and abundance: Ethnoarchaeological evidence from central African forest foragers. Journal of Anthropological Archaeology, 24, 335-353.

Lyman, R. L. (1987). Archaeofaunas and butchery studies: A taphonomic perspective. Advances in Archaeological Method and Theory, 10, 249-337.

Lyman, R. L. (1994). Vertebrate taphonomy. Cambridge: Cambridge University Press.

MacDonald, D. W. (Ed.). (1984). The encyclopedia of mammals. Oxford: Oxford University Press.

Marean, C. W., Abe, Y., Frey, C. J., \& Randall, R. C. (2000). Zooarchaeological and taphonomic analysis of the Die Kelders Cave 1 layers 10 and 11 Middle Stone Age larger mammal fauna. Journal of Human Evolution, 38, 197-233.

Marks, A. E. (1968). The Sebilian industry of the second cataract. In F. Wendorf (Ed.), Prehistory of Nubia (pp. 461-531). Dallas: Fort Burgwin Research Center and Southern Methodist University Press.

Meadow, R. H. (1980). Animal bones: Problems for the archaeologist together with some possible solutions. Paléorient, 6, 65-77.

Mochi, U., \& Carter, T. (1971). Hoofed mammals of the world. New York: Charles Scribner's Sons.

Nowak, R. (1999). Walker's mammals of the world (6th ed.). Baltimore and London: The Johns Hopkins University Press. 
Osypiński, P., \& Osypińska, M. (2015). Optimal adjustment or cultural backwardness? New data on the latest Levallois industries in the Nile Valley. Quaternary International. doi: 10.1016/j.quaint.2015.09.033.

Osypiński, P., Osypińska, M., \& Gautier, A. (2011). Affad 23Middle Palaeolithic site in Southern Dongola Reach, Sudan. Journal of African Archaeology, 9(2), 177-188.

Osypiński, P., Morley, M., Osypińska, M., \& Kotarba-Morley, A. (2016). Terminal Pleistocene habitation structures and riverine palaeoenvironments of the Middle Nile Valley, Sudan: Evidence from Affad 23. Antiquity 90(352), doi:10.15184/ aqy.2016.110.

Peters, J. (1986). Osteomorphology and osteometry of the appendicular skeleton of Grant's gazelle, Gazella Granti (Brooke, 1871), Bohor reedbuck, Redunca redunca (Pallas 1767) and Bushbuck, Tragelaphus (Pallas, 1766), scripts Ghent

Peters, J. (1989a). Osteomorphological features of the appendicular skeleton of gazelles, Genus Gazella (Blainville 1816), Bohor Reedbuck, Tragelaphus scriptus (Pallas, 1766). Anatomia, Histologia, Embryologia, 18(2), 97-192.

Peters, J. (1989b). Faunal remains and environmental change in Central and Eastern Sudan from Terminal Pleistocene to Middle Holocene times. Mededelingen van de Koninlijke Academie voor Wetenschappen, Letteren en Schone Kunsten van België, Klasse der Wetenschappen, Jaargang 51, Nr. 4, Brussel.

Peters, J. (1992). Late Quaternary mammalian remains from Central and Eastern Sudan and their palaeoenvironmental significance. In K. Heine (Ed.), Palaeoecology of Africa and the surrounding islands (pp. 91-115). Brookfield: Rotterdam.

Peters, J., Van Neer, W., \& Plug, I. (1997). Comparative postcranial osteology of Hartbeest (Alcelaphus buselaphus), Scimitar oryx (Oryx dammah) and Addax (Addax nasomaculatus), with notes on the osteometry of gemsbok (Oryx gazelle) and Arabian oryx (Oryx leucoryx). Tervuren: Annales Sciences Zoologiques, vol. 280

Plug, I. (2014). What bone is that? A guide to the identification of Southern African mammal bones. Pretoria: STN Printers.

Schild, R., \& Wendorf, F. (2010). Late Palaeolithic huntergatherers in the Nile Valley of Nubia and Upper Egypt. In E. Garcea (Ed.), South-Eastern Mediterranean peoples between 130,000 and 10,000 years ago (pp. 89-125). Oxford: Oxbow Books.

Steele, T. E. (2012). Late Pleistocene human subsistence in northern Africa: The state of our knowledge and placement in a continental context. In J.-J. Hublin \& S. McPherron (Eds.), Modern origins: A North African perspective (pp. 107-125). Dordrecht: Springer.

Steele, T. E., \& Klein, R. G. (2009). Late Pleistocene subsistence strategies and resource intensification in Africa. In J. J.
Hublin \& M. P. Richards (Eds.), The evolution of hominin diets: Integrating approaches to the study of Palaeolithic subsistence. Vertebrate paleobiology and paleoanthropology (pp. 113-126). Dordrecht: Springer.

Stiner, M. C., \& Munro, N. D. (2002). Approaches to prehistoric diet breadth, demography, and prey ranking systems in time and space. Journal of Archaeological Method and Theory, 9, 181-214.

Stiner, M. C., Munro, N. D., Surovell, T. A., Tchernov, E., \& BarYosef, O. (1999). Palaeolithic population growth pulses evidenced by small animal exploitation. Science, 283, 190-194.

Stuart, C., \& Stuart, T. (2006). Field guide to the larger mammals of Africa. Cape Town: Struik Nature.

Thompson, J. C. (2010). Taphonomic analysis of the Middle Stone Age faunal assemblage from Pinnacle Point Cave 13B, Western Cape, South Africa. Journal of Human Evolution, 59, 321-339.

Thompson, J. C., \& Henshilwood, C. S. (2011). Taphonomic analysis of the Middle Stone Age larger mammal faunal assemblage from Blombos Cave, southern Cape, South Africa. Journal of Human Evolution, 60, 746-767.

Van Neer, W. (1989). Contribution to the archaeozoology of Central Africa. Annales Sciences Zoologiques (Vol. 259). Tervuren: Musée Royal de L'Afrique Centrale.

Van Neer, W. (2004). Evolution of prehistoric fishing in the Nile Valley. Journal of African Archaeology, 2(2), 251-269.

Van Neer, W., Augustynen, S., \& Linkowski, T. (1993). Daily growth increments on fish otoliths as seasonality indicators on archaeological sites: The tilapia from late Palaeolithic Makhadma in Egypt. International Journal of Osteoarchaeology, 3, 241-248.

Van Neer, W., Paulissen, E., \& Vermeersch, P. M. (2000). Chronology, subsistence and environment of the Late Palaeolithic fishing sites of Makhadma-2 and 4. In P. M. Vermeersch (Ed.), Palaeolithic living sites in Upper and Middle Egypt (pp. 271-287). Leuven: Leuven University Press.

Walker, R. (1985). A guide to post-cranial bones of East African animals. Norwich: Hylochoerus Press.

Walther, F., \& Grzimek, B. (1990). Reedbucks, waterbucks and impalas. In Grzimek's encyclopedia of mammals (Vol. 5, pp. 448-461). New York: McGraw Hill Publishing.

Weaver, T. D., Steele, T. E., \& Klein, R. G. (2011). The abundance of eland, buffalo, and wild pigs in Middle and Later Stone Age sites. Journal of Human Evolution, 60, 309-314.

Wendorf, F., \& Schild, R. (1992). The Middle Palaeolithic of North Africa: A status report. In F. Klees \& R. Kuper (Eds.), New light on the northeastern African past. Current prehistoric research (pp. 39-80). Cologne: Heinrich Barth Institut.

Wolfheim, J. H. (Ed.). (1983). Primates of the world: Distribution, abundance and conservation. Seattle: University Washington Press. 